Illinois State University

ISU ReD: Research and eData

Theses and Dissertations

7-3-2020

\title{
As Good As Woke?: Mutuality And Third Spaces In A Guatemalan Volunteer Tourism Organization
}

Hannah Gdalman

Illinois State University, hgdalman@gmail.com

Follow this and additional works at: https://ir.library.illinoisstate.edu/etd

Part of the Sociology Commons

\section{Recommended Citation}

Gdalman, Hannah, "As Good As Woke?: Mutuality And Third Spaces In A Guatemalan Volunteer Tourism Organization" (2020). Theses and Dissertations. 1287.

https://ir.library.illinoisstate.edu/etd/1287

This Thesis is brought to you for free and open access by ISU ReD: Research and eData. It has been accepted for inclusion in Theses and Dissertations by an authorized administrator of ISU ReD: Research and eData. For more information, please contact ISUReD@ilstu.edu. 


\section{AS GOOD AS WOKE?: MUTUALITY AND THIRD SPACES IN A GUATEMALAN \\ VOLUNTEER TOURISM ORGANIZATION}

\section{HANNAH GDALMAN}

81 Pages

It is estimated that as many as 10 million individuals participate in international volunteering projects annually (McGehee, 2014). Since its rise in the late nineties and early aughts, voluntourism has drawn the attention of academic and non-academic audiences alike, who have warned of the perils of exploitation, commodification, and white saviorism. This study conducts an issue-focused analysis to examine the extent to which the voluntourism experience has evolved into one of mutuality rather than cultural hegemony. Sixteen semi-structured interviews and participant observation were conducted at a longstanding Guatemalan voluntourism site. Wearing \& Wearing's (2006) Third Space interactive cultural tourism framework was applied to assist in the analysis of the experiences of both the foreign volunteers and the local host community. Through the application of the key concepts of power, culture, values, place/space, people, and selves, this research examines the co-production of experience within the destination site. Results suggest that while participants, including the outwardly politically conscious volunteers, aspire to create a voluntourism environment that fosters positive social change, the presence of foreign volunteers perpetuates an underlying cultural hierarchy of giver/receiver that is reflected most plainly through the accounts of host community members. KEYWORDS: voluntourism; Guatemala; host community; mutuality; third spaces; Stevenson Center 
AS GOOD AS WOKE?: MUTUALITY AND THIRD SPACES IN A GUATEMALAN

VOLUNTEER TOURISM ORGANIZATION

HANNAH GDALMAN

\author{
A Thesis Submitted in Partial \\ Fulfillment of the Requirements \\ for the Degree of \\ MASTER OF SCIENCE \\ Department of Sociology and Anthropology \\ ILLINOIS STATE UNIVERSITY
}

2020 
(C) 2020 Hannah Gdalman 


\title{
AS GOOD AS WOKE?: MUTUALITY AND THIRD SPACES IN A GUATEMALAN VOLUNTEER TOURISM ORGANIZATION
}

\author{
HANNAH GDALMAN
}

COMMITTEE MEMBERS:

Marion Willetts, Chair

Frank D. Beck

Michael Dougherty 


\section{ACKNOWLEDGMENTS}

This study would not have been possible without the ongoing guidance and mentorship of Dr. Marion Willetts. I cannot thank her enough for her empathetic demeanor and countless hours of reviews. I also thank Dr. Michael Dougherty and Dr. Frank D. Beck for providing continuous support. I am grateful to the Department of Sociology and Anthropology and the Scott Elliot Travel Award for helping fund my whirlwind data collection. I would also like to thank the staff of the Stevenson Center for Community and Economic Development and the Financial Health Network for their ongoing support through this process.

Additionally, I would like to thank my wonderful cohort-I could not have gotten through year one without you. None of this would have been possible without the love of my friends and family, my little William and Kevin, and especially my endlessly supportive and steadfast partner, Gus - this is for you, for standing by my side through this crazy journey.

Finally, thank you to all the volunteers and community members who welcomed me in with open arms and gave me, an unknown researcher with a vague topic and a voice recorder, their time and their words. I couldn't help getting swept away by this group of rugged, worldly young travelers who reminded me so much of myself and the independent, fearless, and sociable person I strive to be. To the community members who took time away from the important work they do every day — thank you for your attention and respect. I'll come back and wash dishes someday.

H.G. 


\section{CONTENTS}

Page

ACKNOWLEDGMENTS

TABLES

CHAPTER I: AS GOOD AS WOKE?: MUTUALITY AND THIRD SPACES IN A GUATEMALAN VOLUNTEER TOURISM ORGANIZATION 1

$\begin{array}{ll}\text { Introduction } & 1\end{array}$

$\begin{array}{ll}\text { Literature Review } & 4\end{array}$

The Rise of Voluntourism $\quad 4$

The Motivations Behind Voluntourism $\quad 4$

$\begin{array}{ll}\text { A Geography of Need } & 6\end{array}$

A Move Towards Adaptancy

$\begin{array}{ll}\text { The Scientific Phase } & 10\end{array}$

$\begin{array}{ll}\text { Theoretical Framework } & 12\end{array}$

$\begin{array}{ll}\text { Methods } & 17\end{array}$

$\begin{array}{ll}\text { Participants } & 17\end{array}$

$\begin{array}{ll}\text { Procedure } & 17\end{array}$

$\begin{array}{ll}\text { The Setting } & 19\end{array}$

$\begin{array}{ll}\text { Analytical Strategy } & 20\end{array}$

$\begin{array}{ll}\text { Results } & 21\end{array}$

Selfish or Selfless: Perceptions of Volunteer Motivations 22

No White Saviors: Perceptions of Volunteer Wokeness 28

'Pariah or Panacea?': Perceptions of Voluntourism as a Practice 33 
Discussion

Conclusion

CHAPTER II: AUTHENTICITY AND THE VOLUNTOURIST 59

$\begin{array}{ll}\text { Authenticity and Tourism } & 59\end{array}$

$\begin{array}{ll}\text { Authenticity and the Voluntourist } & 61\end{array}$

Guatemala: An Authentic Destination $\quad 62$

$\begin{array}{ll}\text { Local Happiness } & 63\end{array}$

The Calm of the Wild $\quad 65$

$\begin{array}{ll}\text { Romanticized Chaos } & 67\end{array}$

$\begin{array}{ll}\text { Conclusion } & 68\end{array}$

$\begin{array}{ll}\text { REFERENCES } & 70\end{array}$

APPENDIX A: INFORMED CONSENT FOR VOLUNTEERS 77

APPENDIX B: INFORMED CONSENT FOR HOST COMMUNITY MEMBERS 79

APPENDIX C: SEMI-STRUCTURED INTERVIEW GUIDE FOR VOLUNTEERS 80

APPENDIX D: SEMI-STRUCTURED INTERVIEW GUIDE FOR HOST COMMUNITY

$\begin{array}{ll}\text { MEMBERS } & 81\end{array}$ 


\section{TABLES}

Table

Page

1. Host Community Member Demographic Information 58

2. Volunteer Demographic Information 58 


\section{CHAPTER I: AS GOOD AS WOKE?: MUTUALITY AND THIRD SPACES IN A GUATEMALAN VOLUNTEER TOURISM ORGANIZATION}

\section{Introduction}

Volunteer tourism, or voluntourism, is a type of alternative tourism that blends volunteer work with travel. Wearing (2001, p. 1), in his oft-cited definition, explains voluntourism as a mode of travel that focuses on "aiding or alleviating the material poverty of some groups in society, the restoration of certain environments or research into aspects of society or environment." It is estimated that as many as 10 million individuals participate in international volunteering projects annually (McGehee, 2014). Voluntourism gained popularity in the late 1990s among young Westerners on gap year - a year-long break between secondary and postsecondary school during which students participate in a variety of experiential activities such as travel or work - and quickly spread first in the UK, followed by Australia, New Zealand, and North America (Lyons et al., 2012). Voluntourism has continued to grow in popularity among a more diverse range of ages and demographics (Leonard \& Onyx, 2009; Molz, 2017; Ulmer, 2015), sparking a growing body of research and popular discourse on the topic.

Wearing and McGehee (2013) have noted that academic research on voluntourism has followed the same four-stage evolution as mainstream tourism: 1) the advocacy phase, during which researchers focused on the positive potential of voluntourism while emphasizing the altruistic motivations of its participants; 2) the cautionary phase, in which newly critical research began to focus on the potential pitfalls and negative social impacts of voluntourism; 3) the adaptancy phase, during which research turned to uncovering specific ways to maximize benefits and minimize negative impacts of voluntourism; and 4) the scientific phase, during which 
researchers began to adopt diverse methodological and theoretical approaches to understanding voluntourism. Arguably, as the academic study of voluntourism has expanded, it is this cautionary platform that has sparked the most attention among academic and non-academic audiences. The perils of voluntourism - the exploitation and commodification of locals and volunteers (Molz, 2017; Vrasti, 2013), the creation of economic dependency between the developing and developed worlds (McGehee \& Andereck, 2008), and social media-fueled white saviorism (Mostafanezhad, 2013) — spark the same sense of contempt for voluntourism as Boorstin (1964, p. 117) showed for the commodification, frivolity, and "fabricated adventures" inherent in mainstream mass tourism.

The purpose of this study is to contribute to the scientific phase of the research by addressing the following research questions: What are the perceptions and experiences of host community members and volunteers within a voluntourism organization, and how are they similar or different? Does voluntourism have the capacity to effect positive social change through the cross-cultural experience? These questions will be addressed by focusing inductively on the experiences of foreign volunteers and local hosts within the context of a longstanding Guatemalan volunteer tourism site. This research embraces the agency of both voluntourists and hosts and acknowledges that the voluntourist experience is shaped by its participants just as much, if not more so, than the experience shapes its participants' outlooks on development, humanitarianism, and culture. Whereas much of the research in voluntourism focuses primarily on the volunteer experience, this research argues that voluntourism is better understood by focusing on the interactions among volunteers, host community members, and the destination site, aligning with previous calls for research that includes the host community perspective (Burrai et al., 2015; Raymond \& Hall, 2008; Sin, 2009; Zavitz \& Butz, 2011). 
More specifically, this project will examine these intersections of experience through semi-structured interviews with foreign volunteers and local hosts, paired with participant observation at the voluntourism site. By eliciting participants' perceptions of the issues at play within the broader discourse of voluntourism and observing the daily interactions that unfold at the volunteer site, this research will examine the co-production of identities within the destination site and whether and how these identities reflect a move towards mutuality rather than cultural hegemony.

Results from this case study suggest that while participants, including the outwardly politically conscious volunteers, aspire to create a voluntourism environment that fosters cultural mutuality and hybridization, the presence of foreign volunteers perpetuates an underlying cultural hierarchy of giver/receiver that is reflected most plainly through the accounts of host community members. In terms of structure, a discussion of the literature concerning the rise of voluntourism and volunteer motivations is presented, followed by a discussion of the theoretical framework and the research methods, which outlines the research design and analytical approach. Results are organized into four main issues: participant perceptions of volunteer motivations; perceptions of volunteers' sociopolitical and cultural awareness with regard to voluntourism; perspectives on voluntourism as a practice; and reflections on their own voluntourism experience within the context of the case study organization. The paper concludes with an overview of the analysis, a discussion of the limitations, and implications for future research. 


\section{Literature Review}

\section{The Rise of Voluntourism}

Voluntourism arose against the social backdrop of globalization, increased connectivity, and a newly urgent call for environmental stewardship. Voluntourism "purports an infusion of an ideological divergence from the market-driven priorities of mass tourism... [which] seems to converge well with the societal needs of the fast-paced, stress-driven contemporary world" (Brown, 2005, p. 493). Similarly, Pearce and Coghlan (2008, p. 134) posit that the rise of voluntourism came about due to Generation Y's "heightened awareness of global problems, sustainability issues, and related travel opportunities fostered by internet services." Scholarly work on voluntourism as a standalone topic began in the late 1990's/early 2000's and has continued to expand. Research has focused on three main components to voluntourism: the voluntourist, the host community (or the "voluntoured"), and the voluntourism organization, with a growing emphasis on the interplay between these stakeholders within the destination site (McGehee, 2012).

\section{The Motivations Behind Voluntourism}

In the advocacy phase, much of the early research on voluntourism found volunteer motivations to be largely positive and rooted in altruism (Brown, 2005; Callanan \& Thomas, 2005; McIntosh \& Zahra, 2007). Wearing (2001) also found altruism to be a common motivating factor, along with a desire for personal and professional development and a general desire for adventure. This "reciprocal altruism," or altruism accompanied by self-benefitting factors, is indicative of an emphasis on the experiential value of voluntourism as well as its practical humanitarian aspect (Söderman \& Snead, 2008). Reciprocal altruism also points to a "climate of increasing freedom of choice," in which prospective volunteers weigh costs and benefits in a 
way that "resembles consumerism" (2008, p. 119). This would explain why the reciprocal benefits of the volunteer experience are often emphasized in the verbiage of voluntourism agencies' marketing materials (Guttentag, 2009, p. 540; Hogan, 2015). According to Vrasti (2013, pp. 29, 121), voluntourism represents "the blurring of economic and ethical values," in which neoliberal volunteers seek to "enhance their professional skills and overall employability" while at the same time tapping into their "genuine desire to do good."

Coghlan and Fennell (2009) further examined altruism as a primary motivating factor for voluntourists. They posit that voluntourist motives are egoistic as well as altruistic and offer the Greek Eudaimonia as a potential alternative in describing voluntourists' motivations. Eudaimonia posits that "true happiness is found in the expression of virtue, in doing what is worth doing, and leads to spiritual and personal fulfilment and the actualization of human potentials" (2009, p. 394). Akin to MacCannell's (1973) work, Mustonen (2006) similarly compares voluntourism to the traditional pilgrimage by employing the concept of the liminoid; whereas pilgrims seek a shift from the profane to the sacred, the voluntourist seeks a shift from the mundane of everyday life to the confrontation of the "other." These voluntourists, in other words, seek the reciprocal benefit of heightened personal and spiritual fulfillment rather than tangible skills or resume fodder.

Other researchers have found voluntourists to be largely motivated by potential selfbenefits (such as the accumulation of soft skills or the reaping of cultural and/or social capital) and "not outwardly centred on contributing to the host-communities" (Coren \& Gray, 2012; Lyons et al., 2012; Molz, 2017; Simpson, 2004; Sin, 2009, p. 490; Vrasti, 2013). While voluntourists seek the experience for a multitude of reasons, including altruistic goals, emotional goals, or more "vacation-minded" goals, many understand that stamps in a passport are not 
sufficient; but "by developing multicultural sensibilities or mastering cultural tensions... a requirement for all workers who wish to enter the ranks of the middle class," they better their chances of success in the modern economy (Vrasti, 2013, p. 130).

Other theorists challenge the assumption that voluntourism is a singular phenomenon and instead demonstrate the wide range of variability within, on both the part of the tourist and the voluntourism organization. Brown (2005, p. 493), for example, differentiates between "volunteer-minded" and "vacation-minded" voluntourists. Drawing from the theories of Maslow and Pearce, she identifies a divide in which "volunteer-minded" tourists display more altruistic motivating factors, whereas "vacation-minded" tourists are more motivated by Maslow's lowerlevel needs "such as love and social needs." Callanan and Thomas (2005) employed a framework adapted from Arne Naess' work on ecology to distinguish between shallow, intermediate, and deep voluntourism. A "shallow" voluntourist prioritizes self-interest and destination over an interest in contributing, whereas a "deep" voluntourist prioritizes altruistic motives and a high level of contribution to destination hosts. The same framework is applied to voluntourism projects, in which shallow projects require little skill and are quite flexible in their needs, and deep voluntourism projects require high skills and time commitments with little to no flexibility.

\section{A Geography of Need ${ }^{1}$}

Currently, the gap year industry promotes an image of a 'third world other' that is dominated by simplistic binaries of 'us and them,' and is expressed through essentialist clichés, where the public face of development is one dominated by the value of western 'good intentions' (Simpson, 2004, p. 690).

As an influx of travelers from the Global North traverse the Global South, questions of cultural hegemony and postcolonialism arise, and with them, the cautionary phase of

\footnotetext{
${ }^{1}$ Simpson, 2004: 686
} 
voluntourism research (Wearing \& McGehee, 2013). There is a tacit notion within voluntourism of the savior and the saved, in which the savior hails from the Global North, and the saved from the Global South (Conran, 2011). The idea of the "white savior" has permeated popular media and is even satirized on the popular Instagram account "Barbie Savior" (Wearing et al., 2018). Mostafanezhad (2013) identifies popular celebrity Angelina Jolie as a white savior archetype and examines how images of her caring for darker-skinned children have been recreated by noncelebrity Western women across social media platforms. She extends Urry's (1990) application of Foucault's tourist gaze to argue that the "humanitarian gaze" inherent in voluntourism creates an "implicit hierarchy between givers and receivers, as well as circumscribing who is a legitimate benefactor of aid" (Mostafanezhad, 2013, p. 489). In similar fashion, Hogan (2015, p. 20) examines marketing materials from gap year voluntourism organizations and again finds the commonplace use of imagery of white (primarily female) volunteers caring for darker-skinned children, thus reinforcing the "white savior industrial complex." This white savior theme is problematic to voluntourism in that it reinforces the hegemonic colonial encounter in which ideas such as "intimacy, goodwill and compassion are used to justify and depoliticize the volunteer experience" (Conran, 2011, p. 1464).

Some researchers argue that voluntourism commoditizes the environmental, economic, and cultural aspects of the experience just as much as mass tourism. Voluntouring becomes an amenity in and of itself, going against its "carefully cultivated self-image of decommodification" (Coren \& Gray, 2012, p. 233; Zavitz \& Butz, 2011). Voluntourism can also be seen to commoditize the emotional or sentimental aspects of the experience (Guiney, 2017; Molz, 2017; Mostafanezhad, 2013). This is particularly pronounced in voluntourism that hinges on sentimental connections between volunteers and the voluntoured, such as orphanage tourism 
(Guiney, 2017, p. 132). In these cases, voluntourists seek a particular emotional connection or interaction with the children, which can in turn "commodify children's emotions into a financially exchangeable service," as well as exploit volunteers' emotions in hopes of encouraging more donations.

As the literature in voluntourism took a cautionary turn, researchers also began to examine volunteers' sociopolitical and cultural awareness with respect to their experience at the voluntourism site. One common theme is a tendency among voluntourists to depoliticize their experience by focusing on the sentimental or emotional aspects of the cross-cultural exchange. Mostafanezhad (2013, p. 492), for one, found female volunteers' perceptions to be rooted in sentimental colonialism, in which feelings of love, care, and intimacy took precedence and “questions of politics and power are swept under the rug of innocence." Conran (2011) and Molz's (2017, p. 354) studies further show that volunteer focus on the emotional and individual moral aspect of the voluntourism experience "depoliticizes the social justice agenda of humanitarian work."

The romanticization of poverty, or the conflation of poverty and authenticity, is another theme that surfaces in the literature. In Vrasti's $(2013$, p. 84) examination of multicultural sensibilities among voluntourists in Guatemala, she found that volunteers were apt to romanticize or exoticize the poverty and culture of host community members within their host site. This multicultural appreciation, she argues, was the direct result of a "false dichotomy between authentic meaning and material progress" in which the volunteers conflated cultural riches as a suitable, if not preferred stand-in for material development. Simpson (2004, p. 689) similarly found a tendency among voluntourists to deploy "lotto logic" when encountering poverty in the host site as a way to avoid discussions of inequality or social justice. By ascribing 
wealth or poverty as a matter of "luck," volunteers undermine the structural causes of global inequalities and the very mechanisms that allow them to voluntour in the first place. She argues that volunteer perceptions of "poor but happy" locals called for a pedagogy of social justice within the gap year voluntourism experience (2004, p. 688).

\section{A Move Towards Adaptancy}

Researchers within the adaptancy platform take a more optimistic approach to voluntourism, examining ways it can be an agent sparking social change (McGehee \& Santos, 2005), contribute to community development (Wearing et al., 2005), and create beneficial Third Spaces between guests and hosts (Wearing \& Wearing, 2006). McGehee and Santos (2005) utilize resource mobilization theory to argue that voluntourists are more disposed to social action after their experiences, due to expanded social networks (including host community members) and heightened social consciousness. McGehee's (2012, p. 102) volunteer tourism social movement theory model demonstrates how voluntourism-driven consciousness-raising can spark action and social change, which in turn leads to more voluntourism participation "in a kind of positive hermeneutic circle." She posits that self-efficacy, as both a prerequisite and an end goal to voluntourism, is an important factor in pioneering social movements and can provide an appropriate theoretical measure of one's likelihood to participate in social movements and seek voluntourism experiences. Along the same vein, Palacios (2010, p. 874) explores the potential in voluntourism for positive outcomes, particularly through the creation of "intercultural

understanding." Interestingly, Palacios views the emphasis on development work as interrupting or detracting from this potential positive outcome and argues that voluntourism experiences should be reframed as "service-learning" rather than development work, as the former involves ideas of "reciprocity and mutuality" that are lacking in the latter (2010, p. 874). 
In A Phenomenology of Tourist Experiences, Cohen (1979, p. 183) lays out a five-part typology of the various "modes of touristic experience" - the recreational mode, the diversionary mode, the experiential mode, the experimental mode, and the existential mode - in an attempt to illustrate how tourism can be simultaneously viewed as a frivolous pleasure by some and an authentic pilgrimage by others. Under this typology, recreational and diversionary tourism experiences provide the modern individual a departure from their everyday experience through entertainment or distraction from their alienation, whereas experimental and existential tourism experiences provide the tourist with new meaning or purpose through authentic interactions. Wearing et al. (2008) challenge Cohen's (1979) five modes of tourist experience to assert that while most types of tourism do not result in personal change, voluntourism, with its emphasis on the experiential and existential, indeed contributes to voluntourist perceptions of self. Voluntourism, framed as an active leisure activity, can be a transformative, interactional experience that can "invoke change in individuals" through the interactions voluntourists have within their host community (Wearing et al., 2008, p. 69).

\section{The Scientific Phase}

The research agenda in voluntourism has continued to expand its methodological approaches, which include qualitative focus groups (McGehee \& Santos, 2005; Zahra \& McGehee, 2013), qualitative case studies (McGehee \& Andereck, 2008; Mustonen, 2006), mixed-method participant observation (McIntosh \& Zahra, 2007; Zavitz \& Butz, 2011), content and website analysis (Coghlan \& Fennell, 2009; Hogan, 2015; Zahra \& McGehee, 2013), and more involved ethnographic forays (Conran, 2011; Mostafanezhad, 2014; Vrasti, 2013). Beyond the notable dearth of macro-quantitative data on this topic, Wearing and McGehee (2013, p. 122) 
call for "the utilization of structured, interdisciplinary, transdisciplinary, transnational, and mixed method approaches to examine volunteer tourism in a more systematic and logical way."

Within this scientific phase, voluntourism has continued to develop in new theoretical directions. Some examples of theoretical contributions within voluntourism include equity theory (Burrai et al., 2015; Pearce \& Coghlan, 2008), community capitals theory (Zahra \& McGehee, 2013), critical theory (McGehee, 2012; Simpson, 2004; Vrasti, 2013), social movement theory (McGehee \& Santos, 2005), feminist theory (Wearing et al., 2005), and decommodification theory (Wearing \& McDonald, 2002). The social theory of voluntourism is still developing, and some researchers have called for a better-suited, all-encompassing theory (McGehee, 2012; Wearing \& McGehee, 2013).

As demonstrated above, there has been a significant amount of scholarly debate surrounding key issues such as volunteer motivations, ways that voluntourism promotes commodification and white saviorism, and how and whether voluntourism lends to personal or societal transformation. What is lacking in the literature is a more dedicated focus on the host community experience, particularly with regard to the co-creation of identities between voluntourists and host community members within the context of the voluntourism site. The aim of this case study is to situate itself firmly within this scientific platform by seeking to better understand the experiences of both volunteers and host community members using a comparative analytic approach, guided by an interest in how these experiences contribute to reciprocity and mutuality and/or cultural hegemony. 


\section{Theoretical Framework}

Wearing and Wearing's (2006) Third Space tourism model provides a helpful framework in interpreting the results of this case study. For one, the foundation of Third Space theory relies on the mutual representation of tourist and host and understands that voluntourism (as an alternative tourism) cannot be properly evaluated or improved without considering the experiences of all stakeholders. Second, Third Spaces can emerge within many cross-cultural contexts, thereby allowing a broad and flexible definition of voluntourism. Lastly, the theoretical underpinnings of Third Space tourism allow the research to address the macro-level questions of postcolonialism and neoliberalism while simultaneously recognizing the importance of the micro-level experiences of tourists and hosts. Through the application of the key concepts of power, culture, values, place/space, people, and selves, this research will be better equipped to isolate the nuances in how volunteers and hosts perceive their experiences, and whether and how these perceptions signal a broader move away from postcolonial "cannibalistic" tourism and towards a more positive interactive and reciprocal tourism.

Alternative tourism, according to Wearing and Wearing (2006), can enable stakeholders to overcome the cultural hegemony inherent in postcolonial tourism by fostering Third Spaces of experiential interaction between tourist and host community. A Third Space, according to Bhabha's (1994) discourse, is a space or intersection in which individuals and cultures interact, and in so doing, dismantle the cultural hierarchy that colonialism would dictate. This usage of Third Spaces is not to be confused by the third places (sometimes referred to as third spaces) within the areas of community building and urban sociology, which are physical environments outside of an individual's usual two social environments, namely home and the workplace (Oldenburg, 1997). Touristic Third Spaces, on the other hand, are the tourist-host interactions in 
which "destination communities' views are considered and given some credence," thereby challenging dominant conceptions of "difference" and "otherness" inherent in neocolonial touristic experiences (Wearing \& Wearing, 2006, p. 147). In Bhabha's (1994) Third Spaces, culture becomes hybridized because the culture of the tourist is no longer assumed to be better than or presiding over the host culture. Rather than "cultural cannibalism," in which Western culture consumes and destroys the host culture, the alternative tourism experience changes the subtext from one of giver-receiver to one of mutuality. These Third Spaces are most likely to flourish in tourist spaces "when social value and identities are developed within the host's cultural presentation" (Wearing \& Wearing, 2006, p. 147). Social value hinges on the degree of host community involvement, with higher involvement in decision-making and implementation leading to higher social value. Identity shifts are successful insofar as they transcend cultural dichotomies and stereotypes to allow a "re-presentation of host community identity" as well as a reimagination of the tourist from being a fleeting voyeur to "an embodied being whose self is changed in some way by the interactions that take place in the tourist space" (2006, pp. 148, 152).

Wearing and Wearing's (2006) model of Third Space interactive tourism centers on six key bases of comparison between Western society and host society: power, culture, values, place/space, people, and selves. In Third Space tourism (as opposed to cannibalistic tourism), power is distributed equitably, rather than rooted in economic dependence. This means that instead of "economically powerful tourist marketeers" who commodify the tourist space through the "rearrangement and trivialization of cultural ceremonies, festivals, and arts and crafts," alternative tourism, through a more mission-driven approach, bestows the power (and profits) upon the host community to craft their own narrative, while encouraging tourists to "respect and 
be sensitive to the people who are hosting the visit" $(2006$, pp. 150,158). An example of this could be a locally owned eco-lodge that sources local building materials, food, and goods, thereby offering tourists a more "authentic" experience while supporting the local economy and offsetting the environmental degradation associated with mass tourism.

Secondly, in Third Space tourism, culture is hybridized rather than based on hegemonic control. Similar to power, alternative tourism provides space for host communities to share their culture through education and interpretation on their own terms, and frames culture as an interactive process in which tourists and hosts learn from each other without destroying or denigrating the host culture as a lesser "other." The tourist space is thus reframed as one in which to learn and interact, rather than an image or a place on display. These learning moments might occur within a local homestay, for example, where tourists learn about local customs, language, and cuisine, while the "educator" hosts learn about their guests' preferences and backgrounds. In this example, Western values are centered around exploration and learning rather than profit, and the host society can focus on maintaining its cultural values. Tourists, instead of voyeurs, become engaged "choristers," while hosts become educators rather than objects to be observed (Wearing \& Wearing, 2006, p. 159).

Finally, the Western self no longer consumes the inferior host society "other;" instead both parties incorporate new aspects from the other's culture into a hybridized, collective "we." The former is often explained as the "demonstration effect," by which destination communities are influenced to imitate affluent tourists' consumption patterns, often at the expense of their own culture and contentment (Guttentag, 2009, p. 547). In the context of voluntourism, an example of this might be host community children who copy Western volunteers' culturally illicit behaviors such as drinking alcohol or smoking, or a local community that, upon observing 
volunteer styles of dress, begin importing clothing at the expense of local producers. Whereas the demonstration effect is unidirectional and therefore erasive of host culture, hybridization implies a mutual shift among both tourists and hosts. Cultural hybridization can be seen as a romanticized view of globalization, in which local communities pick and choose aspects of other cultures, resulting in global heterogeneity rather than homogeneity (Ritzer, 2011). An example of cultural hybridization would be volunteers buying and wearing local textiles to complement their Western clothes, or host community eateries using locally sourced ingredients in their adaptations of American pancakes or Polish pierogis.

In the context of voluntourism, some researchers see Third Spaces as an automatic result of the cross-cultural interchanges inherent in the experience. Zahra and McGehee (2013) found that voluntourists' involvement in a Filipino host community created Third Spaces of bridging and bonding social capital. Whereas bridging social capital occurs when established community groups reach out and connect with outside groups or institutions to seek resources, bonding social capital occurs when relationships and networks grow within a singular community group. Bridging and bonding occurred partly through what the researchers coined the "novelty effect." Volunteers, who are "different and interesting" due to being from outside of the host country, provoked community members to engage and participate in community activities, thus engaging and participating more with their fellow community members and being more inclined to help one another, demonstrating bonding social capital (2013, p. 34). This, in turn, led to an increase in other facets of community capital within the destination site, including built capital in the form of volunteer-assisted construction of playgrounds and roads, natural capital through improved litter removal services and volunteer-inspired trash pickup events, cultural capital through increased attendance at local cultural pride festivals, and political capital through increased 
political solidarity and influence over local leaders. Wearing et al. (2008) similarly investigated how voluntourism can contribute to improved perceptions of self among voluntourists, extending Cohen's (1979) typology of tourism experiences in which the experiential tourist is one who seeks fulfillment through discovering ways in which others live authentically. They assert that voluntourism, despite being a leisure activity, can invoke change and "encourage the individual to think more for himself/herself," which is achieved when voluntourists are immersed "in the context of 'otherness' and removed from the influence of traditional reference groups" (Wearing et al., 2008, p. 69).

Alternatively, the volunteer tourism organization may need to take a more active role in ensuring a mutually beneficial experience. Applying critical theory, McGehee (2012) argues that voluntourism provides a Third Space for the emancipation of both voluntourists and host community members. The host community's emancipation, however, is bound up with that of working and middle-class voluntourists, who, due to the long work hours, rampant consumerism, and increased reliance on technology are "more economically comfortable but nevertheless emotionally and spiritually hamstrung" and in desire of "genuine human interaction" (2012, p. 94). The level of emancipation within the voluntourist space depends upon both the opportunities for emancipation of the "proletariat" voluntourist (through transformative experience, consciousness raising, and increased sense of agency) and the organization's actions to equalize power inequalities between tourists and hosts (2012, p. 98). Raymond (2008) similarly emphasizes the role of the volunteer sending agency in ensuring a mutually beneficial experience for tourists and hosts, something he cautions is not an automatic result of all voluntourism projects. He asserts that "volunteer selection, predeparture preparation, orientation and 
debriefing" as well as an understanding of the importance of the relationship with host organizations, better sets the stage for these mutually beneficial Third Spaces (2008, p. 55).

\section{Methods}

\section{Participants}

This research argues that voluntourism is best understood by focusing on the interactions among volunteers, host community members, and the destination site and therefore involves two samples of participants: 1) local host community members and 2) foreign voluntourists. Over the course of the two-week field study, a total of sixteen participants were interviewed - eight Guatemalan host community members and eight current or former volunteer guides. All host community participants had been born and raised in Guatemala, had direct ties to the organization, and included salaried staff, volunteers, and past residents of the children's home (see Table 1 for more information). All eight volunteers interviewed were white, came from Western countries, and were either in the process of completing, or had already completed, the minimum three-month term as a volunteer trekking guide (see Table 2 for further information). Erin was the only notable exception among the volunteers, as she had been hired as the semipermanent volunteer coordinator in exchange for a stipend.

\section{Procedure}

This research employed an ethnographic, inductive approach to data collection. Voluntourism is a social process that is shaped and defined by the interactions between volunteer, host, and destination place (Wearing, 2001). Qualitative methods, by approaching the social world through an interpretive, naturalistic lens, are best suited to explore how a social experience "is created and given meaning" (Denzin \& Lincoln, 2005, p. 10). Additionally, 
ethnography, as Vrasti (2013, p. 15) posits, is "particularly well-suited to capturing the inherent fluidity of travel."

Research was conducted at a single pre-selected voluntourism site in Guatemala. Prior to the data collection period, the researcher communicated with both the organization's volunteer coordinator and its local founder to explain the purposes of the case study and to request permission to conduct the proposed research. Arrangements were subsequently arranged for onsite accommodation during the fieldwork period. Following Institutional Review Board approval, the researcher traveled to the site, and data were collected through semi-structured interviews and participant observation during a two-week stay. In-situ convenience sampling was employed for volunteer participants, and snowball sampling was employed for host community members. Volunteer participants were initially recruited on site. The researcher, upon taking up residence at the guide house, explained her purposes to the group and recruited volunteers to participate in one-on-one interviews at a place and time of their choosing. For local participants, the researcher initially met with the founder of the organization (prearranged via email) who provided an interview as well as an informal list of community members. The researcher recruited participants from this list, and, upon completion of each subsequent interview, requested the contact information of additional community members for further recruitment.

Interviews were approximately one hour in length; interviews with volunteer tourists were conducted in English, and interviews with host community members were conducted in Spanish. All interviews were digitally recorded with the participants' permission and transcribed verbatim by the researcher (for interview guides, see Appendices C and D). To ensure confidentiality, all subjects have been assigned pseudonyms, as has the host organization. 
Participant observation was also conducted at the host site for the purposes of data collection. According to DeWalt and DeWalt (2002, p. 8), participant observation "enhances the quality of the interpretation of the data, whether those data are collected through participant observation or by other methods." Participant observation was conducted daily at the guide house, during four evening events involving the volunteers and the children's home residents (two soccer nights and two dinners), throughout a three-day, two-night trek, and during solo visits to the school and children's home. Fieldnotes were logged by hand in a notebook or the researcher's smartphone "notes" application and transferred nightly to a word processing program on the researcher's personal laptop. Fieldnotes and personal jottings assisted the researcher in forming a deeper understanding of the daily activities and day-to-day experiences of participants, process her own sentiments and reactions, and formulate early interpretations of the data. Participant observation included interview participants as well as volunteers, host community members, and tourist clients who were not included in the interview component of the research. All participant observation occurred in a public setting and the researcher did not hide her purposes or status as a resident researcher.

\section{The Setting}

VolunTrek was founded in 1995 by a Guatemalan social worker and two British expatriates, with the aim of helping solve the issue of homelessness and lack of education among Guatemala's vulnerable urban youth population, many of whom had been orphaned and left homeless as a result of the recent Civil War. The trio founded a nonprofit urban elementary school with the aim of educating the city's most vulnerable youth and equipping them for successful futures. After several failed attempts at securing funding through various local resources and social business models, the team began offering volunteer-guided treks to 
adventurous tourists seeking to experience Guatemala's volcanos and mountains in a safe and organized manner. The model took off and VolunTrek was born. Over the course of the following years, profits earned from treks funded the construction of a children's home (to house and provide basic necessities for vulnerable children and teens) and an expansion and relocation of the nonprofit school. Currently, the school provides a top-tier education to over 200 local students for a nominal fee to their families. The children's home also houses and cares for 26 children aged ten through seventeen. Profits from VolunTrek hiking trips, which continue to be led by predominantly foreign volunteer trekking guides, account for just over half the organization's annual revenue.

In 2019, VolunTrek hosted a total of 31 volunteer guides, ranging from a high of 18 guides in March to a low of 5 guides in September. VolunTrek guides all live in a modest boarding house near the city center. The boarding house contains the VolunTrek office, a gear storage room, a communal kitchen/common room where volunteers cook meals, play music, and use the internet, and several floors of basic dormitories. The guide house is located approximately 20 minutes walking distance from the children's home, and a 20-minute bus journey from the non-profit school. Therefore, volunteer guides typically interact with host community children and resident workers only twice weekly: on Wednesdays when they meet up at a local stadium to play soccer and Thursdays when they have a communal dinner. The location and cooking responsibility between the guide house and the children's home are alternated weekly.

\section{Analytical Strategy}

An issue-focused analysis was conducted (Weiss, 1994). The focus of the semi-structured interviews was to better understand participants' perceptions of volunteer motivations, as well as 
volunteers' sociopolitical and cultural awareness regarding voluntourism. Attention was also devoted to eliciting participants' perspectives on voluntourism as a practice, both within the context of their own organization and in general. Lastly, interviews focused on drawing out participants' reflections on their own voluntourism experiences.

Per Weiss (1994), the analysis followed four distinct analytic processes: coding, sorting, local integration, and inclusive integration. Following Charmaz (2006), interview transcriptions were coded through a two-stage process: first by open coding the data using gerundial phrases, and second by synthesizing and sorting these first-order codes into a subset of overarching emergent themes, such as the concepts of "wokeness," authenticity, and host community selfdenigration. Data were sorted and locally integrated using color-coded spreadsheets, keeping the volunteer and host community data separate, but paying attention to overlapping or similar second-order themes. Inclusive integration was conducted through an iterative drafting process; as volunteer and host community data were pulled together using these second-order themes and the four guiding issues detailed in the previous paragraph, shared themes related to Third Space mutuality and/or cultural hegemony rose to the surface. These themes were further refined and reconceptualized using Wearing and Wearing's (2006) model and key concepts such as power, culture, and self.

\section{Results}

Key themes emerging from the data, such as reciprocal altruism, wokeness, and transformation, showed important and complex similarities and divergences in the way volunteers and host community members co-construct their experiences. While volunteer accounts centered on the self-actualizing power of their liminal experiences, which they framed as unique and different from "bad" voluntourism, host community member accounts, while 
emphasizing the mutual benefits voluntourism has brought to their community, also articulated a cultural hierarchy within which they self-identify as the "other." These findings are elaborated below with respect to volunteer and host community member perceptions of volunteer motivations, volunteer "wokeness" (that is, the sensibility to racial or social discrimination and injustice), and voluntourism as a practice, as well as participant reflections on their own voluntourism experiences within the context of VolunTrek. These reported experiences contribute to the scientific platform by examining the extent to which VolunTrek stakeholders overcome the system of cultural hegemony within which the organization operates. Findings further advocate for the inclusion of the host community viewpoint in future research on voluntourism.

\section{Selfish or Selfless: Perceptions of Volunteer Motivations}

When asked about their motivations for seeking the VolunTrek experience, volunteers reported being motivated less by altruism and more by the prospect of personal development and recreation. Many volunteers saw their time at VolunTrek as an opportunity to begin a new chapter in their lives. These volunteers came to VolunTrek during a period of transition: having recently graduated, having left a job with which they were unsatisfied, or taking a year off to travel and reflect. Johan, a guide from Denmark, discussed how his decision to travel was sparked by dissatisfaction with his job back home:

I was contemplating life and looking at whether I was doing the right thing for myself, and like going towards my goal in life. And I realized that I wasn't, so I decided, like, sat down and [asked myself] if you really could do anything... what would I do? And I wanted to travel, and trek and hike. and I remember this company I did a trek with 10 years ago.

Similarly, Tori, the newest guide at the organization, traveled to Guatemala from Australia after having recently graduated from university: 
I really like hiking and so I'm here. And traveling also. It's made up a huge part of my last four years. I just needed a break before I started off looking for a full-time job or figuring out if I want to go back and do a master's or not.

For long-time volunteer guide John, getting fired from his bartending job was the pivotal moment that sparked his desire for a change:

I ended up...pretty much eventually got fired from my job, sold everything, came to Guatemala, and yeah that kind of began my whole new life here as kind of outdoor adventure lifestyle rather than like shit American lifestyle.

For these volunteers, VolunTrek represents more than a voluntourism stint—rather, it represents a slice of a broader transitionary period in which personal transformation or betterment, adventure, and novelty all rise to the forefront. Akin to Mustonen's (2006) conceptualization of voluntourism as a postmodern pilgrimage, VolunTrek volunteers seek a shift from the mundane of their everyday lives to the confrontation of the "other." For VolunTrek participants, this “other" they seek isn't necessarily their embodied Guatemalan counterparts but rather the authentic setting of the voluntourism site that represents a departure from their own status quo. VolunTrek, in this way, becomes a liminal space where volunteers enter an all-consuming “placelessness and timelessness” (Mustonen, 2006, p. 172) en route to something else, or as John put it, "here, it's like [volunteers] understand that this is different than their life... when you're here you're not focused on anything else." The underlying condition of the liminal space, however, is its impermanency_volunteers are drawn to VolunTrek as a transitionary moment in their broader life journeys.

Additionally, the physicality of the VolunTrek experience attracts challenge-driven volunteers-VolunTrek guides are often expected to hike five to six days per week, up to twelve hours per day, carrying packs weighing up to half their body weight. In fact, inability to "keep up" during treks was cited as the top reason prospective volunteers were turned away. Michael, 
an ex-volunteer back for his second stint, exemplified this attention to personal development through physical challenge:

I'd rather be here, smelling bad and you know, eating beans fifteen times a week, than working some summer job and being bored, you know?... It's rewarding on a personal level to know that you can put in this crazy amount of hard work for weeks on end and get through it. It's kind of like achieving a personal goal over and over and over again.

VolunTrek attracts volunteers that thrive in the physically and mentally demanding territory of long hikes, sleep deprivation, bug bites, and blisters. While volunteers spoke of being motivated by their love for the outdoors and hiking, they also spoke of the positive results they expected would come with hiking full-time for three months, including an improvement in physical fitness and guiding skills (discussed further below). This would suggest that VolunTrek volunteers are both intrinsically and extrinsically motivated by the physical demands of their guiding experience.

Other participants chose to volunteer with VolunTrek because they wanted a sense of being part of a community. Many volunteers came across VolunTrek organically through travel or word of mouth and were attracted to the community of practice that VolunTrek represents, something that is all the more valuable for the lonesome or aimless backpacker. Johan describes how the volunteer community can be so "attracting:"

I think a lot of people get very intrigued when they see us because we're all so together and having fun and joking and people want to be part of that so much. I also see that when new people come in, they think 'I wanna be in on this, how do I become in?' So, trying to find something that's theirs and find their place... I actually think that's why so many people keep coming back here, because they got so inspired by the community, that people feel like they become part of something really important.

Johan's comment above demonstrates the social pressure and intrigue that draws volunteers into VolunTrek, but it also muddies the distinction between the volunteer community and the organization's mission — being "part of something important" might have very little to do with 
the VolunTrek mission, but instead might relies predominantly on the camaraderie of the volunteer group. Similarly, John speaks of being drawn to VolunTrek for both the community and the chance to build skills:

I think that was probably the biggest draw was like I get this community, but yeah I also get to do this thing where I've dreamed of being Indiana Jones my whole life so this is an opportunity to learn all the skills I want to learn and be in a guide role, and I definitely was already in love with Guatemala at that point, without a doubt.

Brown (2005, p. 488) also found "seeking camaraderie" as a principal motivating factor among volunteer vacationers, who see benefit in coming together with like-minded individuals to work towards a shared goal. Indeed, many VolunTrek volunteers saw the potential to join a collective, a haphazard family of sorts with a "cool kid vibe," and were motivated to stick around.

Like John above, several participants were drawn to VolunTrek by the prospect of building skills, like Katrina, who saw VolunTrek as an opportunity to build a new skill set and potentially spark a career shift away from her current office-bound work:

I came to VolunTrek kind of like exploring more nature-related work.... My original motivations in coming here were like wanting to get experience in outdoor work and wanting experience in general leadership and crafting the narrative of a trek and stuff. And spending time with kids and working on my Spanish.

Volunteers are cognizant of the opportunity VolunTrek presents to build skills that might otherwise require expensive certification courses or prolonged apprenticeships in their home countries. While VolunTrek advertises that it prefers volunteers who have relevant skills (like first aid, guiding hikes, or speaking Spanish), applicants are rarely turned away. Volunteers have a considerable opportunity, therefore, to acquire hands-on experience in a collaborative and intensive environment.

Although volunteers often cited more self-centered motivations, such as skill-building (e.g., wanting to gain trekking skills/leadership skills or improve Spanish language abilities), or 
personal enjoyment (e.g., wanting to trek full-time), rather than altruistic motives for seeking their VolunTrek experience, they also expressed a desire to do good while factoring in personal interests and potential self benefits. Johan, for example, explains how he was primarily motivated by his love of hiking, exemplifying reciprocal altruism:

Actually like for me, at least, it's maybe not so much actually for the good of the niños, like for me it's more I love to hike and it's this good opportunity to do it, I think, and then, of course it's a plus that you can help out the kids, and you get to know the kids, but my primary reason wasn't to do that.

Similarly, Liam, a volunteer from Australia, explains how acting in self-interest helped him decide to enlist in VolunTrek over other local volunteer organizations:

I kept beating myself up, sort of saying to myself, well it's not about you, that's what the point of volunteering is, it's to like give yourself up for another cause. But when I applied that 'be selfish' thing suddenly it was simple. I was like, I'll go straight back to that one [organization] I found on day one that sounded awesome. Why would I not do that? And I think that is one of the key driving factors in why there's so much energy here and why it works so well and has worked so well since '95.

While volunteer motivations are not the sole determinant of mutuality within the voluntourism experience, reciprocal altruism, following Liam's logic above, serves to attract volunteers who are motivated primarily by personal goals and are therefore more willing to work hard and maintain motivation throughout the volunteer experience, which in turn provides more benefits to the host community. To these volunteers, the costs and benefits of the volunteer experience are more likely to balance out, with the added bonus of a higher mission or purpose. But what of the host community?

Interestingly, host community members were more likely to characterize foreign volunteers as seeking satisfaction and transformation through selfless service and cultural exchange. Fernando, having seen thousands of volunteers come and go over the years, explains how their time in Guatemala acts as a type of "social therapy": 
[The volunteers] have it all, and this causes them to be tired, depressed. So, they want to leave their country, and even better if it's a Third World country like here. They come with the intention that they can't give money, they can't change the world, but they can give of themselves through volunteer work.

Similarly, Gladys, the owner of the guide house, spoke of the satisfaction volunteers must experience when "they come with the intent to help, to learn, and they leave with the satisfaction of doing so. Of having participated and helping the kids." Indeed, Fernando's perception of volunteers as wealthy but depressed aligns with McGehee's (2012, p. 94) conceptualization of the working- and middle-class "spiritually hamstrung proletariat" of voluntourists who seek liberation through authentic and rewarding experiences. Both John and Johan's accounts of becoming VolunTrek guides harkened to this idea of seeking something bigger or better than their unfulfilling lives back home. As John puts it, "it's not back home where you're working a shit job or living in a place you don't wanna live... your life here is just filled up with stuff, but it's almost exclusively stuff that brings you value."

Despite host community members' recognition that volunteers may be seeking the experience for reasons more heavily rooted in escapism or, as Fernando aptly puts it, "social therapy," volunteers remain ingrained in the narrative used to motivate children (either in the home, at the school, or both) to work hard and strive to improve their lives. Don Julio, a longtime homestay host along one of the hiking routes, commented on how bringing residents of the local children's home along on treks serves as a great motivator for them:

It also makes me happy when I see [local kids on the treks] because this is the only way they'll appreciate it... Upon experiencing a trek, they say oh, I'm going to fight. I'm going to fight because others are fighting for us to succeed.

Fredy similarly recalls admiring the volunteers during his time at the school and children's home: 
Knowing that there are people who want to help and want to see you better yourself. For me it's something worthy of admiration. That there are people that come here, give their time, so that you can learn or so you can go to school.

This is not to say that host community members were unaware of the reciprocal benefits gleaned by their volunteers. Fernando knew that ex-volunteers often use VolunTrek as a reference on their resumes, whereas Gabriela, the VolunTrek staff accountant and ex-resident of the children's home who works closely with the guide house, understood that guiding "is a diversion to them that they enjoy." However, these mutual benefits were framed as secondary to the ultimate goal of helping others in need. Whereas volunteers reported a reciprocal altruism characterized primarily by selfish motivations, host community members instead characterized volunteers as fundamentally altruistic, followed by more self-serving reciprocal benefits.

\section{No White Saviors: Perceptions of Volunteer Wokeness}

Nearly three decades into the widespread practice of voluntourism, there has been little discussion of how voluntourist perspectives have been impacted by the evolving sociopolitical landscape of international volunteering. This research suggests that the increasing tendency to denounce voluntourism as a practice in popular discourse has indeed influenced the way in which VolunTrekkers approach their experiences and define their roles within their host community. Namely, volunteers seem aware of the nuances of "giving back," acknowledging that, for one, good intentions do not result in de facto good results. Being "woke," according to the Oxford English Dictionary, is to be alert to racial or social discrimination and injustice, popularized by the Black Lives Matter movement ("Woke, Adj.2," 2017). Riley, an American who volunteered at VolunTrek nearly ten years prior to our interview, introduced this concept of volunteer wokeness: 
Ten years ago, fewer people were woke to identity. Especially what it means to be white people, predominantly white people guiding on land that's not ours in any way shape or form...I mean it's kind of a sketchy proposition.

Here, "wokeness" connotes an awakening, in which volunteers come to realize and grapple with the broader implications of their actions, their racial and cultural identities, and their ability to traverse borders in pursuit of personally fulfilling experiences.

Overall, current volunteers were eager to demonstrate their awareness of the sociopolitical implications of white, global northerners volunteering in non-white, global southern contexts. Michael draws on past experiences volunteering with his family to explain how voluntourism can be harmful:

I think a lot of international volunteering is kind of voyeuristic and is not actually designed to help these communities in the best way that it can. But it's really designed to sort of, make white people feel good about helping the world and it can actually have a lot of negative impacts on the places that they go to.

VolunTrek volunteers strive to differentiate themselves from the types of volunteers who, as John puts, it, are "going somewhere, digging wells, and then putting the photos on Facebook." John's sentiments get at the hermeneutic circle within voluntourism, where voluntourism brochures and websites as well as volunteer social media accounts and blogs continually reproduce images whose subjects suggest a dichotomy of white giver and nonwhite recipient (McGehee, 2012; Mostafanezhad, 2013). His critique also points to a nuance around the intent of these photos - in the case of well-digging Facebook posts, the underlying aim is to create a public representation of a particular self-narrative characterized by compassion and empathy, therefore aligning with the dominant consumer culture of "sentimental colonialism" (Wearing et al., 2018, p. 507). This is, interestingly, not all that different from photos posted to the volunteermanaged VolunTrek Instagram account littered with photos of trekkers against mountain backdrops, sunrise silhouettes, mud-caked hiking boots, and smiling local children, which 
centers the role of the volunteer and suggests a thread of sentimental colonialism with respect to not only the local children, but the local wilderness, as well.

Disclaimers like Michael's serve to show how "wokeness" forms the backdrop for participants' cross-cultural accounts, while simultaneously protecting them from the increasingly prevailing criticism against voluntourism. When participants discussed their perceptions of Guatemala, many were careful not to romanticize local poverty, despite striving for an authentic local experience. Participants also spoke of racial power dynamics, acknowledging their whiteness and the privilege they know comes with it. Counter to Simpson (2004), many participants seemed cognizant of, if not burdened by, the structures in place that allowed them to have their experience as a VolunTrek volunteer. Katrina, for example, recognized that her lived experience feeling safe in Guatemala did not necessarily mirror that of locals:

I mean [the threat of danger in Guatemala] is real. That people are unsafe and don't have the resources they need. But because I'm a white person coming here from the U.S. for three months to be a trekking guide, I don't really have to live that experience or feel threatened by the real dangers that a lot of [local] people have.

Similarly, volunteers demonstrated a "wokeness" when discussing their interactions with the local children, and many expressed concerns about how their twice weekly interactions with them (soccer night and dinner night) might lend to negative emotional effects when volunteers inevitably leave, creating a "revolving door of volunteers." Volunteers weighed these impacts carefully and seemed cautious of adopting overtly paternalistic attitudes. Erin refers to a previous volunteer experience to explain this nuance:

I felt way weirder doing that, like, as a white person going to these super remote neighborhoods and pulling up once a week with this mobile school and not really-it was a very strange dynamic. Whereas here I really like that all the interactions we have with the kids are just, like, no, we're paying Guatemalan teachers who know how to teach you better than we do, we've got psychologists in the home that know how to help you. But we love to play soccer and you love to play soccer, let's play soccer together, and we 
need to eat dinner and you need to eat dinner, let's eat dinner together. It's much more a friendship relationship rather than trying to help.

Furthermore, volunteers largely viewed the weekly events with the children as more of a benefit to themselves than to the children, insofar as they serve as an ongoing motivator by bringing tangibility to their day-to-day labor. Liam explains that these weekly interactions, despite being “one of the pricklier situations here... reminds you why you're here and I think that's really important, because it's so easy to get lost in your own individual story." Volunteer wokeness, however, dictates that the volunteers reflect critically on the quality and manner with which they interact with the local children, therefore differentiating themselves from the well-intentionedbut-naïve volunteer narrative portrayed in popular discourse.

Host community members, unlike their volunteer counterparts, were not apt to discuss the neocolonial critique of voluntourism nor the racial implications of being recipients of foreign volunteer aid. When asked about the paucity of local volunteer guides, host community participants cited a lack of volunteering culture among Guatemalan locals as a main driver in their reliance on foreign volunteers. Gladys spoke of this "problem":

Well, the problem here in Guatemala is perhaps that we don't have the culture of helping. Or rather that we haven't thought we needed to help; the culture just doesn't exist here in Guatemala. It's rare that a [local] kid would come and want to help out. They're almost always foreigners.

Maria, the director of the children's home expressed similar sentiments regarding a local indisposition towards volunteering:

Guatemalans really aren't accustomed...for example, if we have spare time and nothing to do, we wouldn't go out and look for places to volunteer. I learned because of my work here with the school - as a teacher I had lots of volunteers coming to my class. But for the will to be there, to be a VolunTrek volunteer...for us to go, 'look, I want to be a volunteer.' That's difficult. That's just not a part of our culture. 
The fact that host community members perceive volunteering as not part of their cultural identity but rather associate it with the foreign volunteers who take part in it has important implications for the way they construct their experience. Whereas some volunteer participants acknowledged that their experience was a direct function of their cultural privileges and the inequalities between Westerners and locals, local participants expressed the "lack of" voluntary action as a cultural deficit, suggesting a level of internalized inferiority. Looking at this a bit deeper, Guatemalans do, in fact, volunteer; for example, before becoming a paid employee, Maria was a volunteer at the children's home. Local high school and college students are also known to volunteer at the children's home and the school to fulfill service-learning requirements. Thus, locals do, indeed, participate in volunteering, so why do they say otherwise? The answer to this question points to the enduring presence of a cultural hierarchy between foreign giver and local beneficiary, as posited by Mostafanezhad's (2013, p. 489) conceptualization of the "humanitarian gaze," in which locals are positioned as the inferior "other." Locals view foreign volunteer guides as inherently different, in fact better, than themselves, placing foreign culture and preferences above their own. Indeed, hiking and backpacking were also reported to be pastimes typical to Westerners, not locals. Gabriela references this local aversion to hiking:

Guatemala also has many, many places to see but unfortunately many Guatemalans don't know their own country. It's because there are many local people who don't like to hike, very few people. Me, I love to hike, I like to visit new places, but that's not the case for many [locals].

While this may be true in some senses (for example, high quality hiking and camping equipment is hard to find in Guatemala, so nearly all of VolunTrek's gear collection is imported through donations and volunteers), it also obscures the fact that many locals do indeed hike and camp, and have been traversing the local terrain for millennia (not to mention the other local hiking companies that are staffed almost entirely by local Guatemalan guides). What was expressed by 
local participants as an aversion to volunteering or hiking is evidence of a persistent tendency towards self-denigration and the elevation of Western culture and whiteness above their own cultural identity. Host community members, by justifying the presence of foreign volunteers in this way, are ascribing to the very white saviorism that the "woke" volunteer participants denounce. This would in turn suggest that the ongoing presence of volunteers has served to perpetuate this cultural hierarchy, thus falling short of Third Space mutuality.

\section{'Pariah or Panacea?'2: Perceptions of Voluntourism as a Practice}

Voluntourism is a liquid construct that has evolved over time, both definitionally and reputationally. In fact, when asked the question, "How do you define voluntourism?", all eight volunteer participants struggled to answer. "Voluntourism," in all its vaguery, leaves them feeling distanced and unsure. As previously discussed, wokeness is entangled in the way volunteer participants frame their experiences, and it also informs the way they define and evaluate voluntourism as a practice. In fact, some volunteer participants refused to define their experience as "voluntourism" altogether. John, for example, argued that his role within VolunTrek was one of agency and responsibility, rather than that of a cog in a machine:

It's not voluntourism 'cause this is an independent organization, people within it are independent, you don't just show up for a week and go hey boss, what do you want me to do?... [Voluntourism agencies] they really just want my money and that's what I think a lot of it is.

Other participants identified with the "volunteer" half of voluntourism, but balked at being identified as a tourist, which implied a level of inauthenticity they fought hard to avoid. An example is Katrina, who actively distanced herself from the superficial "party" lifestyle of tourist clients:

\footnotetext{
${ }^{2}$ Zahra and McGehee 2013: 24
} 
It feels like an honor to get to have that role to take people to see this sacred space for the first time...to emphasize that it has been for thousands of years a sacred space for Mayans and talking about some of the pollution issues and the environmental things and it's nice to - that whole day just feels like super special, yeah. Instead of people just showing up on a shuttle to this super backpack vibe... and just having their party experience and drinking beers by the lake. It's nice to start the day in such a really special way.

Participant aversion towards self-identifying as "voluntourists" lends interesting insight into how they frame their experience. Based on prior literature, VolunTrek volunteers are, by definition, voluntourists. They are traveling "out of the sphere of regular activity to assist others in need," even if they are putting in more work and time than would be the case with other more "shallow" voluntourist projects, according to Callanan and Thomas's (2005) framework (McGehee \& Santos, 2005, p. 760). The term "voluntourism," having borne the brunt of criticism, is continually evolving and being refined through the experiences of the participants. What once started as alternative tourism, or ecotourism, has now shifted into voluntourism and volunteerism, with some volunteer organizations (that have international accreditation and/or academic grounding) now fearing being conflated with the more contentious voluntourism, which, they argue, does not focus on things like sustainability, cultural sensitivity, volunteer preparedness, skill matching, and ensuring the project is locally-informed (Adams, 2020).

Other participants described a value spectrum of bad versus good voluntourism, or as Liam puts it, “there's ethical and there's unethical voluntourism.” Participants' criteria for distinguishing between bad and good voluntourism rest upon three main themes: the nature of the interactions between volunteer and host, transparency around cost, and the length of the volunteer stay. While participants' descriptions of bad voluntourism stem largely from preconceptions about the neocolonial agenda and white saviorism, their notions of good 
voluntourism rest upon the idea of a mutually beneficial experience. John comments on the transformative power of the VolunTrek experience for both locals and volunteers alike:

I always think there's two things we're doing here, like we're helping Guatemalans for sure but we're also helping the people that come here as guides. I think like, for me this experience was super transformative.... Like I can consistently feel so good here and get so many things I want out of life, and deep down I believe I probably am having an impact on people and the kids and stuff.

Within this system of mutual benefits lies the question of price. VolunTrek's volunteer literature emphasizes that it is not "one of those pay-to-volunteer type deals;" instead it emphasizes volunteer work responsibilities and a promise for a rewarding experience. VolunTrek volunteers do not pay fees; instead, volunteers cover their lodging costs at the guide house (roughly \$30-60USD per month) and tip money collected on the hikes is used to buy communal groceries. Erin explains why it is important that organizations like VolunTrek not charge volunteer fees:

I think as a volunteer not paying for your experience is really important, because you're not expecting to get anything out of it more than what you put into it...if I was gonna go and do volunteering and pay $\$ 3,000$ or however much then I would be more inclined to say 'Well I paid so I wanna get this out of it' whereas volunteering shouldn't be like that, it should be that you get out of it what you put into it.

Other volunteers expressed similar sentiments, preferring to donate their time and labor rather than pay fees, thus suggesting an aversion to commodifying their experience. In VolunTrek volunteers' minds, fee-paying volunteers are expendable and interchangeable, whereas their own time and labor are crucial to the functioning of the organization. In short, VolunTrek volunteers feel "needed." Furthermore, this question of price ties in with volunteers' perceptions of transparency, in which the transactional nature of pay-to-volunteer models lends skepticism to how volunteer fees are utilized, and, according to Liam, "a lot of smoke and mirrors." 
VolunTrek, on the other hand, is touted for being transparent with its volunteers as to how its funds are distributed. Tori explains this distinction:

[At other volunteer tourism organizations] you didn't know the organization as well. Whereas like the thing with VolunTrek is that they want you to know everything. They want you to know everything...like all their partners, like everything. Which is really cool to understand that and like where all the money is going and like what they're doing with it.

Alongside cost and transparency, the quantity and quality of the volunteer time commitment weigh into participant perceptions of voluntourism as well. Whereas "bad voluntourism" tends towards shorter-term, superficial experiences, participants value their own experiences for being longer-term and lending towards more authentic connections with locals. VolunTrek's strict three-month minimum commitment is based on the premise that it takes the first month for new volunteers to get fully trained, the second month to gain expertise, and the third month to be a leader and train new recruits. Participants value this longer time horizon and discount the effectiveness of shorter-term volunteer stints. Tori, for example, equates short-term volunteering with tourism:

I would definitely view volunteer tourism, myself, as a very short-term thing. Like that's kind of what tourism is, is like you go somewhere for like a week or something like that and I think in those, even a month is quite a short time, I mean I've done it before, but I, I'd say like a month or less, like you can go, you can do it, you can interact with the locals but you're not really making that much of a difference, I'd say.

This distinction between bad and good voluntourism reveals participants' knowledge of the broader discourse on voluntourism, as well as their inclination to distance their own volunteering experience from more negative perceptions or stereotypes enmeshed in voluntourism. Participants based their categorizations on experiences past and present; some drawing upon previous experiences participating in 'bad' voluntourism, while others pull from anecdotes, popular discourse, or their current experience as a VolunTrek volunteer. Overall, 
VolunTrek was hailed for its positive attributes such as the stringent time requirements and its transparency.

This dichotomized conceptualization of voluntourism was not so apparent in discussions with host community members, whose accounts largely focused on the good side of voluntourism. Host community members spoke of the many benefits foreign volunteers bring both to their organization and to themselves. As a nonprofit, VolunTrek must compete for the funding and recognition necessary to sustain its operations. As an ecotourism operator, VolunTrek has had to compete with an increasing number of local competitors offering similar services. Host community members seemed tuned into the emotional appeal of VolunTrek's mission-driven model, aligning with the literature on fair-trade or responsible/moral tourism, or tourism that supports poverty alleviation in some way (Mostafanezhad, 2014). Fernando, VolunTrek's local founder, explains how the organization found success by leveraging its mission:

This was the secret, more or less. VolunTrek clients knew that everything they were paying for the tours went to the kids. So, they happily paid it, and VolunTrek grew.

VolunTrek's social business ethos sets them apart from local competition and expands their reach to international markets. Volunteer guides (foreign or not) are integral to the organization's non-profit model. While there have been a few Guatemalan guides (Eduardo, for one) sprinkled throughout VolunTrek's 25 years in operation, the vast majority have been foreign volunteers hailing from Europe, North America, Australia, and New Zealand. Host community members see value in hosting foreign volunteers for several reasons. For one, English-speaking foreign volunteers better match the needs of the paying trek clients, who, according to some local participants, are more likely to trust guides that look and speak like them. Fredy, an ex-resident 
of the children's home who currently rents a room in the guide house while attending university, explains:

You know, I think that the foreigners who come by [the office] have a bit more trust when they see the organization and see foreigners like them, you know? For one thing, they speak the same language, and that inspires this level of trust.

This perceived trust in Western volunteers simultaneously suggests a perceived distrust in Guatemalan locals among tourists. Moreover, local participants were well aware of the advertised risks of traveling in Guatemala. Gladys, the owner of the guide house, attributed the current lull in local tourism to this issue of safety:

Another situation that we have here is that Guatemala is a very dangerous country. There's this perception that people will get hurt, and this is another thing that has influenced the downturn in tourism.

This, in local eyes, might partly explain why VolunTrek continually outperforms its predominantly Guatemalan-staffed competitors. If tourists are wary of danger and harm at the hands of locals, then foreign guides become all the more valuable in attracting and inspiring trust among potential clients.

Interestingly, local participants also coupled voluntourism with an increased sense of self-reliance. When asked about her thoughts on VolunTrek's model, Gabriela explained this well:

I think it's more along the lines of sustainable tourism. Because VolunTrek's projectyes, we receive donations from overseas, but the majority of our income is generated here, inside this country, through the hikes that we offer.

The distinction between receiving foreign donations and receiving foreign volunteers that generate funds locally is an important one. As Gabriela alludes to above, the supply of volunteers and hiking clients likely offers a more stable funding source than one-off donations. Additionally, the impacts on the local economy are more tangible, as Gladys describes: 
VolunTrek is self-sustainable because it brings tourism here all year long, not just during certain seasons... it doesn't only help the Guatemalan economy, it helps a lot of people... it doesn't just help the kids, the organizations, it helps us, too. Because the guides go to the local market, they buy the things that they need, and it helps with commerce... it helps give us the means to help.

In this way, host community members do not see themselves as passive recipients of aid, but rather as active participants in a mutual experience. In many volunteer tourism models, there are three stakeholder groups: the host community, the volunteers, and a third-party sending agency that connects groups of volunteers to the host community organization. At VolunTrek, however, there is no sending agency; instead, VolunTrek leadership is directly in charge of determining who comes to volunteer, for how long, and in what capacity. VolunTrek volunteer guides are built into the organization's social business model as a way to generate a sustainable funding source. Volunteers at the school and children's home are given supportive tasks that help lighten the workload on the permanent local staff.

Alongside this emphasis on mutuality, VolunTrek as a host organization has grown and learned over the years that not all volunteers are equally helpful, and have in turn developed processes to control and manage what kinds of volunteers they choose to host. Fernando explains how the volunteer process evolved as the organization grew:

There have always been a few volunteers who don't understand. Overall, we saw this more in the first ten years....we were growing and we made mistakes and they thought that we weren't capable, that we didn't have ideas, that we didn't have a clear vision... not many, but with a few.... Now when a volunteer comes, I let them know the rules, the norms, because there are volunteers who think they want to be a volunteer, and for how long? Three days. Three days just won't do here. They say, 'How about fifteen days?' but they don't know Spanish, so what did they come here to do? Before we'd say okay... but now we say that at least they have some experience in the field of education, the reality of the Third World, above all Guatemala, the culture, that they know something about education and psychology ... it acts as a filter so those that come are actually useful to us.

Fernando's sentiments were shared by other staff at VolunTrek who recognized that volunteers are not all created equal, thus creating a need for screening, training, and the implementation of 
ground rules to ensure that all volunteers contribute meaningfully. This demonstrates that host community members distinguish between the degree of helpfulness of volunteers, similar to the way that volunteers judge voluntourism as "good" or "bad." Secondly, host community members value the agency and ownership they have over VolunTrek's operations, despite the reliance on foreign volunteers.

\section{Transformations and Tradeoffs: Reflections on the Voluntourist Experience}

When asked to reflect on how their volunteer experiences compared to their original expectations, participants were predominantly surprised by the importance of the volunteer community. By design, the guide house at VolunTrek is rigorously insular: guides live together, work together and eat together, and the long work hours largely hinder independent exploration. While some participants were critical of the lack of integration with the local community, the insularity of the guide house serves as a strong ongoing motivator for volunteers. Idle time is scarce at the guide house, and volunteers that don't meet these expectations often meet swift criticism from the group. Volunteers often cited feeling emotionally and physically depleted throughout their stay while feeling beholden to their fellow guides to remain committed to the mission and maintain a steady work ethic. Katrina explains the intensity of the previous cohort and the pressure she felt to match the group-instilled work ethic:

When I first got here- - like a lot of people have been talking about it the past couple of days - like a month ago there was a lot more of 'you have to be working all the time,' and I'd read that sheet that was hanging in the kitchen about time off, and 'you're expected to work $24 / 7$ for three months' and I felt anytime I left the [guide house] I had to ask everyone for permission.

The group dynamic at the guide house not only sets work expectations, but on the rare occasion where personalities clash, it can have an exaggerated effect on volunteer morale. Michael put this well: 
I mean even when it's a great group, you know, people are tired, people are not sleeping like they should be, not eating like they should be and whatnot, and you know, people get edgy and anxious and people flare out and it's tough. It helps as long as the group is good, things tend to run smoothly, but when there's personalities clashing it gets really hard.

Strong friendships forged among volunteers led to other challenges; for example, volunteers often spoke of the emotional toll caused by constantly saying goodbye to fellow guides who were at the end of their three-month foray. At the same time, these intense but fleeting relationships were understood to be par for the course among backpacker tourists, or as Johan put it, "it's part of the traveling life." Nevertheless, guide farewells are ceremonious and emotional, and due to the rolling enrollment process, can happen as frequently as once per week.

Atypical to many voluntourism operations, this sense of community does not rely directly upon interactions with locals. While volunteers sometimes complained about not feeling adequately integrated within the local community, they also cited the surpringly strong friendships forged with their fellow volunteers during their three-month tenures. These strong friendships between volunteer guides may therefore serve to distract or insulate those volunteers who, for lack of Spanish language ability or other factors, might be disappointed or unfulfilled by their inability to form strong bonds with local Guatemalans during their stay. This might also extend Wearing and Wearing's (2006, p. 159) conceptualization of Third Spaces in voluntourism. Recall that Third Spaces are authentic tourist-host interactions that challenge the concepts of "they" and "other" inherent in postcolonial tourism. The VolunTrek volunteer experience might extend this thinking to encapsulate authentic interactions that occur within the host-community context, even if the interactions and relationships occur largely between the foreign volunteers. For one, VolunTrek guides come together from a variety of Western cultures and backgrounds into a commune environment in which volunteers share equal responsibilities, 
resources are pooled and shared, and decisions are made collectively. The volunteer community is hybridized and fluid, and encourages exploration, learning, and growth, rather than productivity, rankings, or profit. In short, the guide collective at VolunTrek fosters many of the values and power dynamics inherent in Third Space tourism, despite a marginal focus on volunteer-host interactions.

When asked about whether and how their volunteer experience has changed them, all volunteers cited positive transformations, including increased self-confidence, new or improved skill sets, stronger connections to the local land and people, and new or more palpable plans for the future. Liam, who was interviewed on his last day at VolunTrek, cited improved mental health and coping skills from long bouts of illness during his three months, as well as a newfound urge to evangelize the VolunTrek model of voluntourism:

I wanna see this given to the world. This little office in other random cities scattered around. Like, people need to know about this and how well it works... Like if people are given, handed this model, if we hand this model to like passionate, like good, passionate people, like there's that hope that they will, yeah, take it and found this in other places supporting different causes. I'd love to see that happen.

Riley discussed how her VolunTrek experience bore significance throughout the ten years since:

It's definitely true that my time here I was just like in love with everyone. I was in love with the work, with this life, with this city, with these streets, with these people. Even if those weren't deep relationships... so I think that just feeling amazed and like, sort of a general enthusiasm for Guatemala back then definitely informed the way I've thought about the unfolding Central American crisis over the last decade. And have always felt, and you know been in relationship with Guatemalan immigrants in my work, doing wage-theft work from a legal services perspective.

The fact that volunteers' personal accounts were so rhapsodic suggests for one, that their experiences met, or exceeded, their original expectations. Their positive perceptions may also have been influenced by the pivotal or transitional nature of their experiences; as "postmodern pilgrims," volunteers are especially poised to make progress towards a self-actualization of sorts 
(Mustonen, 2006). Furthermore, the tendency among volunteers to express a "love" for the locals and Guatemala as a country points to a level of sentimentalism or a "humanitarian gaze" that masks the underlying unequal power dynamics between volunteer and host community member (Mostafanezhad, 2014, p. 4).

This is not to say that volunteers had no criticisms of the model. Some participants, particularly those who had been at VolunTrek the longest (like John, Johan, Michael, and Erin), identified areas for improvement at VolunTrek. Erin, for example, connected the lack of locals involved in the VolunTrek guiding operation with rumored resentment from locally staffed competitor guiding operations:

I think we're a little bit, everyone who has been involved in VolunTrek for long enough has said that there's resentment towards us [from local competitors] because we're the foreigners that come in, everyone knows that we have more clients than anyone else, there's some suspicion from people that the school even exists or the children's home even exists.... And I think that the fact that we don't really have local people coming in feeds into that because nobody knows who to talk to or who to trust.

Although it is unclear whether this rumored tension is founded in truth, as coordinator, Erin has made steps to change it, most notably bringing youth from the children's home along on weekend treks (as to not interfere with their school schedules), as well as recruiting part-time local volunteers to help guide hikes on occasional basis without having to commit to living at the guide house full time.

Others, like volunteers Johan and John, worried about local leadership impinging on volunteer freedoms at the guide house. Pooled volunteer tip money, which until recently was kept at the guide house and used for communal needs at the discretion of the volunteers, recently began getting funneled through the local administrative offices, likely for accounting purposes. Johan, however, felt that this was an unnecessary exertion of control by local leadership: 
I think it's control. But I actually don't know, I just heard this. Is that necessary? It's our money. I guess he [Fernando] can do it because he owns the organization. It's just kind of strange... Like it kind of takes that feeling of it being ours away. Because he wants to handle the money. I don't know.

John, who was a VolunTrek volunteer long before the implementation of the volunteer coordinator role (of which Erin is only the second), similarly lamented the loss of an "all-handson-deck" mentality at the guide house:

That's not at all what this is about, this is an opportunity in life for you to not have a human resources department or a boss to go to handle the situation...this is not a place where it should just be handed off to someone and like thanks for doing that for me, you're the boss, like thanks. No, you're missing that. You're missing that opportunity.

John and Johan's desire for a scrappy, grassroots operation speaks to several important points. For one, it points to the ongoing importance of independence and agency for volunteers. Recall that this sense of independence aligns with volunteers' conceptions of "good voluntourism," in which volunteer work is skilled and essential (in contrast to bad voluntourism, where volunteer work is largely symbolic). Additionally, a more "corporatized" voluntourism operation belies volunteers' expectations in terms of authenticity of experience, insofar as this authenticity hinges on a departure from that which is associated with modern western culture. Lastly, and perhaps most significantly, these critiques perpetuate a cultural dichotomy of "us" (foreign volunteers) and "them" (local stakeholders) by falsely uncoupling the volunteer guide experience from the local organization at large, as well as suggesting that the former knows better than the latter. Host community member accounts of their experiences centered around several topics: personal change, cross-cultural relationships, tangible benefits, and areas for improvement. For example, Gabriela attributes her openness and cosmopolitanism to her experiences growing up around volunteers:

Imagine. When I arrived at the children's home I brought this idea with me. That [the Gringos] were going to kidnap me... I was shy, I didn't speak, and I didn't understand 
Spanish because I spoke a Mayan language, as well... But these were the people that supposedly kidnapped children... [now] I have many foreign friends. I even live with some foreign friends in their home... I really like to learn about the different customs they bring with them, different ways of thinking, so I like to learn new things.

As Gabriela's account shows, the cross-cultural exchanges between volunteers and locals offer benefits such as the opportunity to learn English and break down cultural barriers, resulting in mutual respect and, at times, lasting friendships. Similarly, Fernando cites how, over time, these interactions have broken down fears and negative stereotypes of foreigners:

[The children at the home and the school] are learning so much about the volunteers' culture. Twenty-five years ago, this whole community, the kids here were all afraid of foreigners. It was the same thing on the treks, they would run when we'd travel through the communities. They were afraid because they thought that foreigners steal children and do bad things, so they were really shy. The whole community was like that. But not anymore. Everything changed, everything.... any of the kids now, it doesn't take much for them to make contact with the volunteers, they've learned and have experienced a cultural shift. Besides that, they learn English.

Notably, Gabriela and Fernando's accounts also point to an undercurrent of self-denigration in the way they emphasize the prior naivete or cultural backwardness among locals. In fact, this anecdote of sheltered villagers misidentifying white backpackers as kidnappers was mentioned to the researcher many times during her field study, by both foreign volunteers and local community members alike. What may initially seem as an inspiring and entertaining tale of transformation also functions to reestablish locals as exotified "others" who are far behind Westerners in terms of development and are therefore justifiable benefactors of volunteer aid. Other local participants like Fredy, Lilian, and Eduardo who grew up in the children's home or school recalled their interactions with Western volunteers fondly. Some noted challenges, however, in maintaining contact with volunteers after they leave. The moment that volunteers leave, notes Lilian, "some automatically lose all communication, and others continue." Eduardo recalled being devastated when a volunteer, who had been a guide with him 
for six months and was "like a brother," left secretly, only leaving behind a note for Eduardo: "I cried all day... why would he leave me like that?" Conversely, those volunteers who do maintain contact, or make return visits, have a strong positive impact on locals. Repeat volunteer John was a clear example of this-local children and community members alike strongly favored him in group interactions, calling him by name and joking with him much more than with other volunteers. Host community participants like Lilian and Don Pedro also boasted of being up to date with past volunteers' lives, referencing photos and updates shared through messaging services and social media.

These same local participants also spoke of the tangible benefits they have received on account of VolunTrek. Among local participants, there is a keen understanding that education is not a given in Guatemala, but a privilege. Lilian, for example, explained that "if it weren't for the VolunTrek school, I wouldn't be studying for my Bachelor's in Nursing right now.” Graduates of the VolunTrek school know that without the scholarships, cost of living stipends, and other support provided by VolunTrek, they likely would not have been able to pursue higher levels of education. Internal stakeholders also spoke of the tangible progress stemming from VolunTrek's work in the community, like Gladys, who noted the palpable downturn in homeless "street youth," and Don Julio, who noted the dramatic improvement in VolunTrek's facilities over the past decade:

Ten years ago, I went to see the children's home they had rented. A very poor house, pardon the word 'dirty.' The kids were there, and we went to play with them, I remember that we did a piñata with them, but they were very, very poor. But after, I was met with a grand surprise. When I went to see the school, a beautiful school. I went to see the children's home, and oh, two levels, a kitchen, everything had changed.

These sorts of success stories were common among local stakeholders. Maria, the director of the children's home, spent a large part of her interview naming graduates of the organization and 
talking about their subsequent successes. Borrowing from Zahra and McGehee's (2013)

community capitals approach to voluntourism, while some host community members pointed to improvements in built capital (physical structural improvements, such as the new school building), the majority discussed improvements in human capital (professional, educational, or skill improvements) and personal capital (improvements in soft skills such as confidence or personal pride).

When asked what they might change or improve about VolunTrek, host community members were more reticent, but one theme that arose was the problem of unemployment in Guatemala. Eduardo, who volunteered at VolunTrek for five years in exchange for a full scholarship for secondary school, called out this issue:

In an ideal world it's really important to be able to generate employment. Because if not, when the kids at the children's home turn 18 and leave, they have to find a job. And perhaps they could integrate VolunTrek's work as some type of work for them. Or there are other kids that study design, and they could design for VolunTrek. Or be porters, VolunTrek porters. That would also create jobs.

Fredy, now 21, experienced this hardship firsthand when he aged out of the children's home at age 18:

I would have liked if they helped us a little when we left, you know... It was a really difficult change because I didn't have relatives who I could count on or live with, so it was really hard to leave there. I didn't have money; I didn't have a job. I didn't have anything, anywhere to live, nothing. So, I had to search. I spent many months searching.

The notion that voluntourism has the potential to take jobs away from locals or create foreign dependency is not a new one (Guttentag, 2009; McGehee \& Andereck, 2008; Vrasti, 2013). The fact that VolunTrek runs its trekking services off the free labor of voluntourists rather than employing locals is a difficult tradeoff. On the one hand, it frees up more funding to support the organization's mission of housing and educating vulnerable youth. On the other hand, it could be 
seen as exacerbating local unemployment if VolunTrek's model of volunteer labor were to gain popularity among local organizations and businesses.

Despite the challenges cited by volunteer participants (such as lack of integration with the local community, emotional burnout from the constant comings and goings of clients and volunteers, and lack of free time), they were largely very satisfied with their experiences at VolunTrek, exemplified by repeat volunteers like John, Erin, and Michael. Host community members were similarly positive in their accounts, citing benefits to themselves and their community over the years. Recall McGehee's (2012) framing of the emancipatory potential of the voluntourism experience for both volunteer and host to overcome the dominant hegemony and lead to social change. Among volunteers, there were indeed indicators of transformative shifts in the form of increased self-confidence, emotional coping strategies, an increased "love" for the local culture, and an increased desire to continue doing social service work in some capacity. However, there was also a persistent tendency to express a paternalistic "love" for locals as well as dichotomize "us" (volunteer guides) and "them" (local stakeholders). Among host community members, there is similarly a thread of increased cosmopolitanism and crosscultural relationships that lead to increased confidence, as well as an increase in a sense of agency over who volunteers and in what capacity (discussed in the previous section). However, there is also a pervasive framing in which the host community members are the recipients of aid, and the volunteers are the givers, suggesting that the power inequalities between volunteer and voluntoured have not yet been eliminated. 


\section{Discussion}

Wearing and Wearing's (2006) theoretical framing of mutuality and Third Spaces in tourism described earlier in this chapter is relevant to explaining the range of perceptions among volunteers and hosts, particularly through the key concepts of power, culture, values, place/space, people, and self. Beginning with the concept of power, Third Space voluntourism would dictate a "more equitable distribution of power," rooted in exchange rather than dependency (2006, p. 160). At its core, VolunTrek fosters an equitable exchange in which volunteers give their time and labor in exchange for a positive, transformative experience. The lack of volunteer fees alleviates volunteer concerns over transparency and allows them to feel needed and valued in their work. Host community members gain a sustainable funding stream, as well as the added benefits that come with having foreign volunteers in their midst. Additionally, host participants hold the power to determine who volunteers and in what capacity (although it remains unclear if and when this power is actually exerted) and are able to generate funding within their own borders. However, among host community members, the perceived need for hiking guides not only suggests some degree of dependency on foreign volunteers, but it is also justified with false claims of host culture deficits, pointing to a tendency among host community members to prescribe to the very white saviorism that volunteers denounce.

The culture at VolunTrek certainly strives to be one of hybridization. Interactions between tourists and hosts are framed as beneficial exchanges. Host community members learn English, host children get to experience trekking, and volunteers express a love of locals and local culture, although it is not clear how much of that love stems from a deep-seated tendency to sentimentalize their cross-cultural encounters. Nevertheless, volunteers eat local food, take local 
transport, are expected to learn, and subsequently teach trek clients, the local historical and cultural context.

Examining the concept of values, volunteer values indeed reflect those of an "imaginative traveler," driven by the desire to explore new bounds, both geographically and personally, or as Michael put it, "people who value experiences more than money" (Wearing \& Wearing, 2006, p. 160). Host community goals of educating vulnerable children in a nurturing, locally run environment would certainly point towards the retaining of cultural values, especially because the school, unlike other area schools, continues to integrate indigenous Mayan language learning into their curriculum.

Looking at the tourism place/space, for volunteers, VolunTrek represents a site of authenticity and challenge in which expectations of learning, growth, and self-improvement take precedence. Volunteers outwardly reject the voyeuristic nature of "bad" voluntourism and pride themselves in being active and receptive to new information, skills, and relationships. Notably, the tourist space for VolunTrek guides is also a liminal space, a transitionary moment for volunteers as they navigate from one life event to the next. This creates a rift, then, between volunteers' temporary experience and locals' permanent reality. Local participants similarly viewed their country as one of great natural and cultural beauty, but equally doubted its capacity for development.

Lastly, examining participant constructions of people and selves, volunteers, as guides who teach tourists about Guatemalan culture, land, and history, are certainly closer to cultural “choristers" than "voyeurs," although, interestingly, their interactions remain largely among fellow volunteers and tourist clients. Host community members walk the line between being educators and objects for observation — especially considering the fact that the local children are 
expected to interact with the volunteers on a weekly basis. As for "selves," recall that within cannibalistic tourism, the tourists define themselves through the use of "I" and "me," thus denoting a self that is "constrained by hegemonic culture" and "consumes and eliminates 'others"” (2006, p. 160). Indeed, volunteers seemed more apt to focus on issues of "I" and "me," including personal aspirations, skill development, growth, and legacy at the voluntourism organization. Their voluntourism experience, while it may have sparked conversations about the highly individualistic cultures back home and the benefits of a more communal environment, did not seem to substantially shift volunteer identities away from the "I" and "me." If anything, volunteers came to view themselves as "VolunTrekkers," a label that encapsulates the collective "we" of foreign trekking guides, thus uncoupling them from their local counterparts.

Voluntouring was their journey to craft and their legacy to create, even if they did so as a "VolunTrekker."

This comes in contrast with host community members, whose sense of self tended more towards the hybridized "we." Host community members also identified strongly with the organization and its mission. They conceptualized the work achieved at VolunTrek as work "we" accomplished - meaning local stakeholders and foreign volunteers united. At the same time, host community members tended to inferiorize themselves when comparing themselves to their foreign counterparts. This would suggest that host community member conceptualizations of self rests somewhere in between that of an inferior "other" and that of a hybridized and fluid "we."

The above framing of Third Space tourism leaves out several key nuances at the core of the VolunTrek experience. For one, Third Spaces, according to Wearing and Wearing's (2006) framework, are directly tied to cross-cultural interactions. In the context of VolunTrek, volunteer relationships are not fully reliant upon interactions with host community members, but instead 
are largely fostered among volunteers. Lasting friendships between volunteers and host community members are not the norm, despite being highly valued among locals. Arguably, insularity among guides leads to an environment that fosters the type of personal transformation discussed by McGehee (2012). This might suggest that comradery among volunteers within the local context might be equally important to the satisfaction of volunteers than curated interactions between tourists and hosts. Cross-cultural interactions instead serve to bring tangibility to their work, re-rooting them in the mission of the organization. It might also suggest, however, that interactions between volunteers and local stakeholders or decisionmakers within the organization are key to preventing volunteers from feeling alienated from their roles. Otherwise, power tensions emerge between volunteers, who desire independence and a grassroots feel, and hosts, who strive to run their operation in a transparent and increasingly efficient manner. Overall, what this suggests is that mutually productive cross-cultural interactions may not occur organically or naturally through these Third Spaces, but rather may need to be carefully curated to balance the needs and desires of volunteers and hosts.

Additionally, volunteer unwillingness to cite purely altruistic motives points to an important nuance in which altruism is associated directly with the well-intentioned but misguided postcolonial conceptions of "bad" voluntourists. Ascribing to a mission is deemed acceptable only insofar as helping is not the primary goal. As "selfish altruists," volunteers ensure that they reap benefits from their experience, while simultaneously distancing themselves from white saviorism. Within the context of VolunTrek, "selfish altruism" supports voluntourism geared more as service-learning in which volunteers' primary goals (like skill-building) are inherently more self-centered and less humanitarian. Host community members, on the other hand, assume altruism is a guiding force among their volunteers. Ideas such as "giving back" and 
"work that matters" come to the fore, corresponding with Mostafanezhad's (2014, p. 31) framing of the "Peace Corps Effect," in which stakeholders are motivated by cultural norms rooted in sentimental humanitarianism, fair trade business models, and a focus on "making a difference one person or village at a time," suggesting a persistent neoliberal ideology.

As a whole, these findings demonstrate important similarities and differences between volunteers and host community members in terms of the ways they co-construct their experiences within a singular voluntourism model, and how these co-constructions speak to the idea of cultural mutuality. In addressing the first research question as to the perceptions and experiences of host community members and volunteers within a voluntourism organization, volunteers paint their experiences as postmodern pilgrims in search of authentic opportunities to build skills, pursue new interests, seek camaraderie, and escape the mundane. Feeding off the increasingly pervasive postcolonial critiques of voluntourism as voyeuristic, commodifying, paternalistic, and shallow, volunteers distinguish their experiences as authentic, deliberate, and based on genuine cross-cultural interactions. This creates dissonance between volunteer knowledge of the potential ills of "bad" voluntourism and the mechanisms of cultural hegemony upon which their own experience is based.

Host community members, unlike their volunteer counterparts, did not have the same criticisms of "bad" voluntourism. Instead, host community members framed voluntourism as a sustainable source of volunteer labor that fills important and unmet local needs and allows them to generate sustainable funding within their own borders, on their own terms. Like volunteers, host community members touted the personal and communal benefits of the cross-cultural exchanges facilitated by the voluntourism experience. Nevertheless, host community members' tendency towards self-denigration points to self perceptions that remain rooted in the unfavorable 
hierarchy of giver/receiver, in which the giver (in this case the volunteer) is framed as "better than." Also persistent was the conceptualization of development as a linear process, in which Guatemala, and the rest of the Global South, is seen as lagging behind the nations in the Global North.

Finally, with regard to the question of whether voluntourism has the capacity to effect positive social change through the cross-cultural experience, this particular case study presents a few key insights. At a high level, the very essence of VolunTrek's social business model is, of course, selling its hikes on the basis of ethical consumption. Since its inception in the 1990's, VolunTrek has reached thousands of foreign volunteers and tourists who have spread its mission in various capacities around the globe. Among volunteers interviewed in this study, many arrived with little to no knowledge of Guatemalan culture, history, or social problems - topics they would inevitably learn and teach to tourist clients along the trekking routes. While some exvolunteers, like Riley, go on to develop careers with distinct ties to their experiences in Guatemala, others return home and become long-term donors for VolunTrek, or inspire people within their social networks to consider joining the ranks as VolunTrek guides or clients. Economically speaking, what these volunteers take away with them has translated into decades of sustainable funding that has supported the continual expansion and improvement of VolunTrek's local agencies. Additionally, the carefully crafted communal authenticity at the guide house lends to a unique environment that fosters big-picture conversations and a collective enthusiasm for the VolunTrek model. This suggests that volunteers who arrive without a strong sense of "good" versus "bad" tourism certainly leave with one, potentially translating into a shifting demand for more ethical voluntourism models and experiences. 
For the host community, the changes resulting from voluntourism were both personal and material. The tangible changes - infrastructural improvements, a wider donor base, etc., are arguably a result of the funds procured by the voluntourists rather than the physical presence of the volunteers themselves. Thus, it becomes the development of soft skills (such as increased self-confidence) that is uniquely tied to hosting foreign volunteers. Of course, cross-cultural exchanges can occur in other forms (homestays, language immersion, tourism, etc.), which would imply that voluntourism is not the only means to this end. Additionally, local stakeholder accounts suggest a gradual reconciliation of host community power over time. As the organization has grown and learned, they have been more cognizant of their agency in determining how the voluntourism organization operates.

While this case study cannot speak to all of voluntourism and its social impacts, it sheds light on a few key insights. Feeless voluntourism models, such as VolunTrek, do indeed allow a focus on local capacity-building, preservation of the natural environment, and a slow-growth non-profit mission without "selling" the volunteer experience or profiting off of volunteer sentiments - all of which would suggest mutuality and positive social change. Overall, while there is certainly evidence that suggests long-term positive impacts from the VolunTrek model of voluntourism, it is also clear that the third spaces of cross-cultural interaction have yet to overcome the dominant hegemony. While volunteer "wokeness" and host community agency point to promising trends, there is a persistent lack of action or a social justice narrative that might allow stakeholders to recognize and reconcile the host community's internalized cultural inferiority. Nevertheless, VolunTrek volunteers' elementary delineation between "good” and "bad" voluntourism could point towards the beginnings of a systematic process by which voluntourism experiences are monitored and evaluated based on criteria that center around these 
very issues of mutuality and decommodification, sustainability, financial transparency, local involvement, stipulations on who volunteers and how, and more.

No study is without its limitations. While active efforts were made to curtail researcher bias, the researcher's own experiences as a long-term volunteer in Guatemala undoubtably had some effect. Additionally, the researcher, who presents as a white, Western, millennial female, was able to quickly and successfully integrate at the guide house. While this surely increased rapport among volunteer participants, it may have had the opposite effect with host community participants, in particular with regard to their candidness when talking about volunteers. Future research would benefit from a second local researcher who would be better poised to draw out honest commentary from host community participants. Third, due to a very strict timeframe within which the data were collected, the researcher was not able to experience a full threemonth cycle at the guide house, which would have likely facilitated a more complete account of the volunteer experience. Fourth, while the researcher was able to interview both volunteers and host community members, the bulk of her time was spent among the volunteers, not the local host community. While this mirrors the volunteer experience, it also may have contributed to a less profound understanding of the host community experience. Finally, this study presents a zoomed-in snapshot of a singular case in a very particular space, time, and setting. The results of this research are therefore not generalizable to voluntourism as a whole, but rather offer important insights and ideas that may be further examined in future research contexts.

\section{Conclusion}

By carefully examining the interplay of experiences between volunteer guest and Guatemalan host, the current study has contributed significantly to our understanding of several 
key themes. First, this research uncovered a important nuance in the ways volunteers and host community members perceive a singular voluntourism experience, which reemphasizes the need for research that considers all stakeholders. Second, this study demonstrates that popular discourse has played an important role in the shaping and altering of voluntourist perceptions and expectations and suggests that volunteers could be particularly receptive to an added focus on social justice and the politics of international volunteering. Third, this study highlights the utility of theory in developing a comprehensive evaluation of voluntourism experiences. As voluntourism has become more and more mainstream, it has also taken on many different shapes and forms. A system for monitoring and evaluating the growing range of operations will be crucial for long-term change.

Voluntourism has important ties within tourism, global development, and the politics of humanitarianism. It is impossible and impractical to view voluntourism as a standalone practice, and it is equally detrimental to overlook the agency and significance of its stakeholders. As the results indicate, the efficacy and sustainability of voluntourism rests largely in its ability to transcend the culturally cannibalistic nature of hegemonic tourism. While this study presents promising evidence that voluntourism can, in fact, produce and support positive social change, it also uncovered persistent symbols of hegemonic control and quiescence. There remains much work to be done to mitigate the cultural hierarchies perpetuated by an ideology rooted in sentimental humanitarianism and cultural dichotomies. 
Table 1: Host Community Member Demographic Information

\begin{tabular}{|c|c|c|c|c|}
\hline Name & Gender & Age & $\begin{array}{l}\text { Country of } \\
\text { origin }\end{array}$ & Stakeholder role \\
\hline Don Julio & Male & 67 & Guatemala & $\begin{array}{l}\text { Owner of a rural homestay on one of the } \\
\text { trekking routes (current) }\end{array}$ \\
\hline Eduardo & Male & Unknown & Guatemala & $\begin{array}{l}4 \text { years as a student at the nonprofit school, } 5 \\
\text { years as a volunteer guide }\end{array}$ \\
\hline Fernando & Male & Unknown & Guatemala & Founder of the organization \\
\hline Fredy & Male & 20 & Guatemala & 10 years as a resident of the children's home \\
\hline Gabriela & Female & 24 & Guatemala & $\begin{array}{l}5 \text { years as a resident of the children's home, } 5 \\
\text { years working in the administrative offices } \\
\text { (current) }\end{array}$ \\
\hline Gladys & Female & 50 & Guatemala & Owner of the guide house (current) \\
\hline Lilian & Female & 24 & Guatemala & $\begin{array}{l}9 \text { years total at the children's home: } 3 \text { years } \\
\text { as a resident, } 3 \text { years as a volunteer, and } 3 \\
\text { years as an employee (current) }\end{array}$ \\
\hline
\end{tabular}

Table 2: Volunteer Demographic Information

\begin{tabular}{|l|l|l|l|l|l|}
\hline Name & Gender & Race & Age & $\begin{array}{l}\text { Country } \\
\text { of origin }\end{array}$ & Time spent at volunteer site \\
\hline Erin & Female & White & 25 & Canada & $\begin{array}{l}3.5 \text { months (contracted for 1 year as } \\
\text { the Volunteer Coordinator) }\end{array}$ \\
\hline Johan & Male & White & 33 & Denmark & 6 weeks \\
\hline John & Male & White & 27 & USA & $\begin{array}{l}\text { 24 months total (comprised of a 15- } \\
\text { month stay followed by 6 weeks, } \\
\text { followed by 7 months, followed by 2 } \\
\text { weeks with departure date } \\
\text { undetermined) }\end{array}$ \\
\hline Katrina & Female & White & 25 & USA & 5 weeks \\
\hline Liam & Male & White & 25 & Australia & 3 months \\
\hline Michael & Male & White & 22 & USA & $\begin{array}{l}4 \text { months when he was 18 years old, } \\
\text { currently 3 weeks into a 10 week stay }\end{array}$ \\
\hline Riley & Female & White & 29 & USA & $\begin{array}{l}4 \text { months (when she was 19 years } \\
\text { old) }\end{array}$ \\
\hline Tori & Female & White & 23 & Australia & 2 weeks \\
\hline
\end{tabular}




\section{CHAPTER II: AUTHENTICITY AND THE VOLUNTOURIST}

\section{Authenticity and Tourism}

Authenticity has long been at the forefront of tourism discourse. Building upon ideas introduced in the previous chapter, this chapter serves to delve deeper into how authenticity factors into the VolunTrek experience. In terms of structure, this chapter commences with a review of theories on authenticity and tourism, which serves to frame the subsequent discussion of authenticity within the context of this study's findings.

MacCannell (1976) was one of the first sociologists to broach its connection to tourism in his framing of cultural authenticity, in which modern alienated workers seek to escape the superficial, bureaucratic drudgery of modern postindustrial life through authentic tourist experiences, much like a traditional religious pilgrimage. He draws from Goffman's front and back regions of social performance, in which actions taken in social "front regions" are performative and meant for an audience (akin to the front stage of a theater) and "back regions" are private and uncensored (much like backstage). In this sense, MacCannell (1973, p. 590) frames tourists as seeking "authentic" or "demystified" experiences by penetrating the back stages of everyday life. To MacCannell, tourism directly reflects the structural differentiation of postmodern society. He writes:

Tourism and participation in the other modern alternatives to everyday life makes [sic] a place for the unattached individuals in modern society. The act of sightseeing is a kind of involvement with social appearances that helps the person to construct totalities from his disparate experiences. (MacCannell, 1976, p. 15)

Not all back stages are authentic, however, but are, as Forster (1964, p. 226) describes, "phonyfolk-culture." Tourist destination inhabitants, wearied by tourists prying into their private lives, put up an artificial façade —what MacCannell (1976, p. 91) describes as "staged authenticity." 
Again informed by Goffman's (1959) theory of impression management, staged authenticity is based on the idea that individuals control how they are perceived by others in the public setting through constructed performances. In the touristic setting, these manufactured impressions might be re-enacted tribal dances or local marketplaces designed for tourist consumption. As tourists maneuver from the front stages to the back, they gain more insight, and their experience becomes increasingly authentic as they penetrate past the simulacra inherent in these constructed back regions (MacCannell, 1973).

As mentioned in the previous chapter, Cohen (1979) also considers authenticity in his typology of the touristic experience. According to Cohen (1979), recreational and diversionary tourism experiences provide the modern individual a departure from their everyday experience through entertainment or distraction from their alienation, whereas experimental and existential tourism experiences provide the tourist with new meaning or purpose through authentic interactions. It is within the latter modes where voluntourism got its rise; it is within this motivation to seek a change in self-aligning with MacCannell's (1976) view of tourism as a postmodern pilgrimage of sorts - where we see the potential for the growth of alternative and niche tourism such as voluntourism (Lyons \& Wearing, 2008).

Wang (1999) extends MacCannell's work in his reconceptualization of authenticity in modern tourism by separating authenticity into three subtypes: objective authenticity, constructive authenticity, and existential authenticity. Examining these categories more closely, objective authenticity dictates that the distinction between authentic and inauthentic is based on objective criteria, such as an object in a museum versus a giftshop replica, or a private Hawaiian luau versus a commercial luau at a tourist resort. With objective authenticity, there is typically an original version of the object/place/event on which to base legitimacy. Constructive or symbolic 
authenticity, on the other hand, is grounded in social consensus and is therefore negotiable, such as the iconic and photogenic Cinderella Castle at the Walt Disney World theme park. Over time, this landmark, despite the absence of an original, has become accepted as an authentic and significant destination for many tourists (also known as "emergent authenticity") (Wang, 1999, p. 355). Finally, existential authenticity is tied to the liminality of the tourist experience itself and therefore becomes a state of being. In other words, existential authenticity occurs when the act of touring — for example, watching a Flamenco dancer in Spain—sparks emotional catharsis or feelings of being "true to oneself," regardless of the objective authenticity of the setting or activity (1999, p. 360). Under this classification, MacCannell's concept of staged authenticity, as well as Boorstin's (1964, p. 117) more critical concept of mass touristic "pseudo events," rely on objective authenticity in which touristic events and toured objects are either real or false/staged. Wang's (1999) conclusion, therefore, is that the objective authenticity of toured objects or events becomes irrelevant if the tourists themselves can contrive symbolic and/or existential authenticity from their own experiences.

\section{Authenticity and the Voluntourist}

As discussed in the previous chapter, seeking an authentic experience is often cited as a primary motivation among voluntourists (Mustonen, 2006; Vrasti, 2013). However, few researchers dive deeper into exploring authenticity as a key framework in the voluntourism experience (Kontogeorgopoulos, 2017). The following section presents findings from this study that illuminate how authenticity is centered within the voluntourism experience. 


\section{Guatemala: An Authentic Destination}

Guatemala is the heart of the Mayan world. Alive, magical, mystical and ancestral. Its history goes back to four thousand years, when the Mayan civilization emerged, whose legacy remains today with the traditions and culture of its people. (Why Guatemala?, 2018)

Guatemala, a small country comprising the northwestern border of Central America, has long been a popular destination for adventurous tourists seeking to explore its colorful markets, its volcanos and other natural wonders, and its living Mayan heritage. Between the years 2009 to 2014, Guatemala hosted a modest 1.2 to 1.6 million international visitors annually (Instituto Guatemalteco de Turismo, 2016). By comparison, the city of Cancun, Mexico, saw 6.5 million international tourists in 2015 (Cordero et al., 2017). Unlike the resort vacationers of Cancun, the international travelers arriving in Guatemala are often looking for a more alternative and/or budget-friendly experience. Therefore, backpacker tourism is alive and well in Guatemala, with budget hostels littering the so-called "Gringo Trail" (The Gringo Trail, 2020). Guatemala is also popular among voluntourists: with approximately 111 newly registered non-governmental organizations in 2018 alone, as well as hundreds of short- and long-term volunteer opportunities listed online, Guatemala is a popular destination for volunteer do-gooders (Registro de las Personas Jurídicas, 2018; Volunteer in Guatemala, 2020).

Overall, Guatemala is commonly perceived as an authentic destination (for the reasons detailed below). In part, it is Guatemala's perceived lack of investment in artificial or mass tourism that has earned it this badge of authenticity. Costa Rica, Guatemala's Central American neighbor, was often used as a cautionary benchmark by study participants of what could happen if Guatemala were to invest more in tourism development and thus sacrifice this authenticity. Fernando puts this well: 
The [Costa Rican] government has done more to support tourism culture, but it's more artificial, I think, in some places. They also have rivers and volcanoes there that are very natural but the difference here is that the culture of [Guatemalan] people is alive and well. Over there in Costa Rica, no. Sometimes [tourists] get confused if it's American or if it's Costa Rican. But here no. We have a culture that's completely unique. Towns that seem like they're from a thousand years ago, a culture from a thousand years ago.

When asked how Guatemala compares with other places he has traveled and volunteered,

Michael, a VolunTrek guide, mirrored Fernando's sentiments:

I love Guatemala. I think it's a really beautiful place. I think there are a lot of problems here. Definitely a lot of issues, especially like socially, and politically. But I think it's incredibly beautiful, the people here are incredibly nice, and it's a very authentic country. Costa Rica just feels kind of like Guatemala but just for tourists. [Costa Rica] kind of feels like the Disneyland of Central America. Yeah Guatemala it's just, you know, it's real. It's authentic, it's beautiful, the people are nice. I love it here.

For both Fernando and Michael, Guatemala's authenticity lies in part due to the fact that it has not been tailored or constructed for tourism alone-instead, it maintains its "realness" in its enduring culture.

While hints of mass tourism such as higher-end chain hotels and organized tours certainly exist across Guatemala's tourist hot spots, much of Guatemala remains rural and undeveloped, which, in many tourists' eyes, equates with authenticity. Across interviews and participant observations with VolunTrek volunteers, three key indicators of Guatemalan authenticity arose: its people, its wilderness, and its poverty. Each of these indicators is discussed below.

\section{Local Happiness}

It is widely accepted among researchers that a key component to voluntourism is the interaction between volunteers and host community members. These reciprocally beneficial cross-cultural interactions, or "intimate encounters," provide authenticity to the voluntourism encounter, and differentiate voluntourism from the more superficial and fly-by mass tourism (Conran, 2011, p. 1463). At the same time, the centrality of the volunteer-host interaction can 
lead to the reinforcement of cultural stereotypes and pernicious "othering," which adds a layer of complexity to the meaning of authenticity (Taylor, 2001).

Among VolunTrek volunteers and host community members alike, cross-cultural interactions were highly regarded and viewed as a beneficial and central part of the experience (see Chapter I). Similar to what Kontogeorgopoulos (2017) found among voluntourists in Thailand, VolunTrek guides often cited local friendliness as a key reflection on their interactions with locals. Here, John describes his first weeks in Guatemala after arriving, having had no prior travel experience, knowledge of the country, nor Spanish language skills:

That family I met like almost immediately had a huge impact on me realizing like how nice Guatemalan people are... Even when I was first traveling around for that week I remember only taking public transport, I had no clue where I was going, everyone would help me, it was just beautiful. And then the country as a whole, it's a country where stuff is super, super real.

Erin, when asked about what she had learned about Guatemala in her three months in country, similarly spoke of the local friendliness:

People, it's like cliché, people's amicability and happiness and openness to foreigners despite the shit that foreigners have put them through, like ultimately... I learned... and am learning constantly about that.

Albeit seemingly harmless, these examples not only further the "poor but happy" narrative often exacerbated by voluntourism, but they suggest that volunteers may not be gaining the sophisticated understanding of their hosts one might expect. Akin to Kontogeorgopoulos' study (2017, p. 8), this points to a superficial understanding of local demeanor that misses the "nuance and depth" of local facial expressions, communication styles, and subtext. The narrative of friendly, happy, and hospitable locals is nothing new, and if anything, does a disservice to the complexity and range of personalities and sentiments of the Guatemalan people. Authenticity, in 
this sense, does not hinge on unveiling new or surprising backstage insights about another culture, but rather relies only on the confirmation of widely held typecasts.

\section{The Calm of the Wild}

Thus, while objective measures of wilderness are few, those that do exist assert meaningful impacts on the character of the landscape, providing an illusion that the site is authentic - a primitive, untouched, pristine wilderness. (Vidon, 2018, p. 223)

A second component in Guatemala's authenticity lies in its natural assets. Known as the country of eternal spring, Guatemala boasts dozens of active and inactive volcanoes, mountain forests, rainforests, beaches, and volcanic lakes (Why Guatemala?, 2018). It is from the tourist interest in accessing these natural riches that VolunTrek got its rise. VolunTrek guides are seemingly united in their love and appreciation for nature and trekking, and for many of them, it was their main motivation in seeking out their VolunTrek experience.

For many volunteers, the departure from their realities back home to the authenticity of the Guatemalan naturescape is the ultimate shift—a shift that represents a personal journey of self-discovery or transformation. Wang (1999) makes this important distinction well— nature/wilderness, rather than being an authentic object sought after by tourists, is the mechanism through which tourists seek their own authentic selves. Like Katrina, a volunteer guide, who measured her journey towards mindfulness with the quantity and quality of time spent in nature:

My first trek...had like a really big party atmosphere, like multiple people brought liquor in their backpacks... people were getting like really drunk and passing around like four different bottles of rum...Having come here from this space where I was all about quiet time in nature and respecting the land, and saying grace before eating, really mindfully interacting with my surroundings...I thought I would be spending like so much nature time here... but it feels like more city time. 'Cause when I'm on treks, it's like very fastpaced, and the lake trek you don't sleep outside any of the nights, so you spend a lot of time hiking but you're not really hanging out in the woods a lot, you know? 
For Katrina, her ability to progress on her personal journey towards authenticity was hindered by the unmatched social expectations of her time in the wilds. The "party" behavior of her trekking clients clashed with her association of wilderness as "a place of truth, peace, quiet, and introspection," therefore threatening the authenticity of her experience (Vidon, 2018, p. 228).

Katrina was not the only volunteer to make the distinction between their time spent out on treks and their time back at the guide house or with the local children. Aligning with Kontogeorgopoulos (2017, p. 16), for VolunTrek volunteers, the Guatemalan wilderness comprises one piece of their "voluntourscape," in which disparate and episodic settings wrap up into a singular authentic experience. These "voluntourscapes" are authentically backstage settings that "blend certain features of everyday life such as routine, order, predictability, and security with elements normally associated with travel such as adventure, novelty, excitement, and alterity." The Guatemalan countryside, in this regard, represents a place in which to tap into these authentic elements such as adventure, excitement, and freedom from institutional power. Johan, the volunteer from Denmark, delineates this well:

I think my favorite part is being out hiking...It's like once you're out there, you're with yourself. Here [in the city], it's always bossing around the office so you never really get that quiet time alone but when you're out there walking that's where you kinda process what's going on in your life and your thoughts and everything and just, yeah, I guess your body's working and you can feel everything that's working and not working in your body, so that's my favorite part for sure.

Because VolunTrek volunteers often spend more time out leading treks than back at the guide house or in other touristic settings, this may further emphasize the importance of the voluntourism context to its success. Volunteers, craving authenticity of experience, must strike a proper balance regarding time spent in these disparate voluntourscapes. 


\section{Romanticized Chaos}

Previous research has shown a tendency among voluntourists to conflate cultural authenticity with poverty (Mostafanezhad, 2014; Vrasti, 2013). In MacCannell's (1973, pp. 589590) view, the touristic search for authentic back stages was, in many ways, a search for "for the sacred in primitive society" in order to counter the "concern of moderns for the shallowness of their lives and inauthenticity of their experiences." In the context of voluntourism, this search for the authentic "other" may take on many different forms (Mustonen, 2006). One of these forms of "otherness" can be that which is "perceived to be beyond the realm of capitalist modernity" (Mostafanezhad, 2014, p. 40). Here, Erin discusses this tendency to romanticize the "chaos" of poverty:

I get that it's so easy for me to romanticize those things coming from Canada and taking all those things for granted and coming here and being like oh, well, yeah the [local] market is so chaotic and hectic and everything but it's so amazing because it's so unlike anything we have in Canada, like everyone's yelling for their fruit and this and that and walking through and seeing the meat hanging up and everything. It's not developed but I-part of me is really like, but it shouldn't be developed! Malls suck, supermarkets suck, like huge things where you're so disconnected from the person who's cutting the meat, or bringing the apples in, or whatever it is.

Here, Erin recognizes that part of the reason she is so drawn to the chaos of the local market is its divergence from all that she is familiar with back home. Herein lies the crux of cultural authenticity for voluntourists like Erin and her fellow VolunTrek guides. The authenticity they seek is perhaps not an object or aspect they desire to gaze upon, but rather the absence of business as usual. In this case, the absence of infrastructural development and Western order amounts to a more authentic setting. Johan also saw authenticity in the local "chaos:"

Like the bus station, just walking in [other tourists] are like 'I wanna get out it's so stressful' and I could just go and hang out a whole day because I just love that chaotic feel. But at the same time people are like super nice and everybody is super friendly like once you get behind the chaos and see it for what it is...I love that beautiful chaotic order. 
Similarly, Tori sees the lack of modern amenities as a good way to practice ingenuity:

I think yeah maybe just because it's different. Different from what I know....I think also because it's a bit rough around the edges, again in some ways less developed they've been able to maintain their culture a lot better...And you learn so much more...like rather than a Western country you can just go out and be like, I'm gonna buy $\mathrm{x}, \mathrm{y}$, zed, and like the power's always gonna be working. Whereas somewhere like Guatemala or like when I was in India, like you may not always have access to everything that you want or everything you need. And then you either come up with, or you like talk to other people and they know like a way around it...I feel like you learn so many little innovative ways to deal with it rather than just being able to have everything instantly.

As Tori and Erin explain above, part of the authentic experience they seek in Guatemala lies in the differences they perceive between the local way of life and their lives back home. Experiencing the chaotic marketplaces and local bus terminals, navigating sidewalks that start and end with no apparent logic, and dealing with the challenges of daily electricity outages and unpotable water all contribute to the "realness" of the volunteer experience. Authenticity, in this sense, is born out of the experience of "roughing it," or living away from the comforts of Western wealth, mirroring the "deep-seated mental association between material comfort and inauthenticity" Kontogeorgopoulos (2003, p. 184) found among backpacker tourists in Thailand. For VolunTrek guides, the charm of poverty and living like the locals brings an important element of authenticity to their experience.

\section{Conclusion}

It is clear that authenticity remains a key issue in modern tourism, particularly alternative forms such as voluntourism. If anything, the quest for authenticity of self has increasingly permeated the modern Western experience economy, in which individuals search with increasing vehemence for deeper meaning, personal transformation, increased wellness and trueness of self. 
A search for authenticity remains a key motivator for voluntourists, who, as described above, seek divergence from their lifestyles in a variety of ways.

Returning to Wang's (1999) typology of objective authenticity, constructive authenticity, and existential authenticity, we see that the latter two take precedence in the case of VolunTrek guides. While Guatemala as a destination represents objective authenticity in its enduring history, culture, and natural landscapes, the volunteer experience is one that emphasizes the personal journey taken when volunteers don the title of "VolunTrekker." For one, the volunteer search for authenticity in cross-cultural interactions relies less on the ability to uncover new or deep understandings of the local culture and rather on the presence of these interactions in and of themselves. Volunteer perceptions of local Guatemalans as happy and hospitable lack depth but do not lead to dissatisfaction of the authenticity of these encounters. This may be partly due to the fact that the VolunTrek guide experience is dominated by time spent out on treks in a wilderness environment that holds symbolic authenticity as being a place or space "outside the dominant institutions... which demarcate the profane from the sacred, responsibilities from freedom, work from leisure, and the inauthentic public role from the authentic self"' (Wang, 1999, p. 361). Additionally, volunteer romanticization of Guatemalan poverty and/or lack of modern infrastructural development points to authenticity based not upon the objects within the tourist space, but rather the dissimilitude from their modern, affluent lives. Additionally, living like the locals and "roughing it" lend to existential feelings that legitimize the "realness" of the experience and allow VolunTrekkers to earn their badges as hiking guides and travelers, rather than mere tourists. 


\section{REFERENCES}

Adams, J. (2020, March 10). 'A genuine difference': Volunteer providers draw line with voluntourism. The Spinoff. https://thespinoff.co.nz/society/10-03-2020/voluntourism-isnot-volunteering/

Bhabha, H. (1994). The location of culture. Routledge.

Boorstin, D. (1964). The Image: A guide to pseudo-events in America. Atheneum.

Brown, S. (2005). Travelling with a Purpose: Understanding the Motives and Benefits of Volunteer Vacationers. Current Issues in Tourism, 8(6), 479-496.

Burrai, E., Font, X., \& Cochrane, J. (2015). Destination Stakeholders’ Perceptions of Volunteer Tourism: An Equity Theory Approach. International Journal of Tourism Research, $17(5), 451-459$.

Callanan, M., \& Thomas, S. (2005). Volunteer Tourism. Deconstructing volunteer activities within a dynamic environment (M. Novelli, Ed; pp. 183-200). Elsevier ButterworthHeinemann.

Charmaz, K. (2006). Constructing Grounded Theory: A Practical Guide through Qualitative Analysis. SAGE Publications, Inc.

Coghlan, A., \& Fennell, D. (2009). Myth or Substance: An Examination of Altruism as the Basis of Volunteer Tourism. Annals of Leisure Research, 12(3/4), 377-402.

Cohen, E. (1979). A Phenomenology of Tourist Experiences. Sociology, 13(2), 179-201.

Conran, M. (2011). They really love me! Intimacy in Volunteer Tourism. Annals of Tourism Research, 38(4), 1454-1473. 
Cordero, E. de la M., Corona Gonzalez, R. G., Solís Trejo, M. T., \& Estrada, S. S. (2017). Turismo en Mexico 2016 (p. 40). Secretaría de Turismo. http://www.datatur.sectur.gob.mx/Documentos\%20Publicaciones/TurismoEnMexico.pdf

Coren, N., \& Gray, T. (2012). Commodification of Volunteer Tourism: A Comparative Study of Volunteer Tourists in Vietnam and in Thailand. International Journal of Tourism Research, 14(3), 222-234.

Denzin, N. K., \& Lincoln, Y. S. (Eds.). (2005). The Sage Handbook of Qualitative Research (Third). Sage Publications.

DeWalt, K., \& DeWalt, B. (2002). Participant Observation: A Guide for Fieldworkers. AltaMira Press.

Forster, J. (1964). The Sociological Consequences of Tourism. International Journal of Comparative Sociology (Brill Academic Publishers), 5(2), 217-227.

Goffman, E. (1959). The Presentation of Self in Everyday Life. Doubleday. Guiney, T. (2017). "Hug-an-orphan vacations": "Love” and emotion in orphanage tourism. Geographical Journal, 184(2), 125-137.

Guttentag, D. A. (2009). The possible negative impacts of volunteer tourism. International Journal of Tourism Research, 11(6), 537-551.

Hogan, J. (2015). Gap year saviours-An analysis of the role of race in an advertisement for development volunteering. Irish Journal of Applied Social Studies, 15(1), 15-22.

Instituto Guatemalteco de Turismo. (2016). Actualización de Series Históricas de Llegadas de Visitantes Internacional 2009-2014 (p. 15). Departamento de Investigación y Análisis de Mercados. http://biblioteca.inguat.gob.gt/Digital/Actest.pdf 
Kontogeorgopoulos, N. (2003). Keeping Up with the Joneses: Tourists, Travellers, and the Quest for Cultural Authenticity in Southern Thailand. Tourist Studies, 3(2), 171-203.

Kontogeorgopoulos, N. (2017). Finding oneself while discovering others: An existential perspective on volunteer tourism in Thailand. Annals of Tourism Research, 65, 1-12.

Leonard, R., \& Onyx, J. (2009). Volunteer tourism: The interests and motivations of grey nomads. Annals of Leisure Research, 12(3-4), 315-332.

Lyons, K., Hanley, J., Wearing, S., \& Neil, J. (2012). Gap year volunteer tourism. Myths of Global Citizenship? Annals of Tourism Research, 39, 361-378.

Lyons, K., \& Wearing, S. (Eds.). (2008). Journeys of discovery in volunteer tourism. [Electronic resource]: International case study perspectives. Wallingford, UK ; Cambridge, MA : CABI, c2008.

MacCannell, D. (1973). Staged Authenticity: Arrangements of Social Space in Tourist Settings. American Journal of Sociology, 79(3), 589-603.

MacCannell, D. (1976). The tourist: A new theory of the leisure class. Schocken Books.

McGehee, N. G. (2012). Oppression, emancipation, and volunteer tourism. Research Propositions. Annals of Tourism Research, 39, 84-107.

McGehee, N. G. (2014). Volunteer tourism: Evolution, issues and futures. Journal of Sustainable Tourism, 22(6), 847-854.

McGehee, N. G., \& Andereck, K. (2008). “Pettin” the Critters': Exploring the Complex Relationship Between Volunteers and the Voluntoured in McDowell County, West Virginia, USA, and Tijuana, Mexico (K. Lyons \& S. Wearing, Eds.; pp. 12-24). CABI International. 
McGehee, N. G., \& Santos, C. A. (2005). Social change, discourse and volunteer tourism. Annals of Tourism Research, 32, 760-779.

McIntosh, A. J., \& Zahra, A. (2007). A Cultural Encounter through Volunteer Tourism: Towards the Ideals of Sustainable Tourism? Journal of Sustainable Tourism, 15(5), 541-556. Academic Search Complete.

Molz, J. G. (2017). Giving Back, Doing Good, Feeling Global: The Affective Flows of Family Voluntourism. Journal of Contemporary Ethnography, 46(3), 334-360.

Mostafanezhad, M. (2013). 'Getting in Touch with your Inner Angelina': Celebrity humanitarianism and the cultural politics of gendered generosity in volunteer tourism. Third World Quarterly, 34(3), 485-499.

Mostafanezhad, M. (2014). Volunteer Tourism: Popular Humanitarianism in Neoliberal Times. Ashgate Publishing Company.

Mustonen, P. (2006). Volunteer Tourism: Postmodern Pilgrimage? Journal of Tourism and Cultural Change, 3(3), 160-177.

Oldenburg, R. (1997). The great good place: Cafés, coffee shops, community centers, beauty parlors, general stores, bars, hangouts, and how they get you through the day ([2nd ed.]). Marlowe \& Co.

Palacios, C. M. (2010). Volunteer tourism, development and education in a postcolonial world: Conceiving global connections beyond aid. Journal of Sustainable Tourism, 18(7), 861878.

Pearce, P. L., \& Coghlan, A. (2008). The Dynamics Behind Volunteer Tourism. In K. Lyons \& S. Wearing (Eds.), Journeys of discovery in volunteer tourism: International case study perspectives (pp. 130-143). CABI Publishing. 
Raymond, E. (2008). 'Make a Difference!': The Role of Sending Organizations in Volunteer Tourism. In K. Lyons \& S. Wearing (Eds.), Journeys of Discovery in Volunteer Tourism: International Case Study Perspectives (pp. 48-60). CABI Publishing.

Raymond, E., \& Hall, M. (2008). The Development of Cross-Cultural (Mis)Understanding Through Volunteer Tourism. Journal of Sustainable Tourism, 16(5), 530-543.

Registro de las Personas Jurídicas, Organizaciones no Gubernamentales. (2018). Ministerio de Gobernacion. https://uip.mingob.gob.gt/wp-content/uploads/2017/03/Numeral-29Organizaciones-No-Gubernamentales-Inscritas-Julio-2019.pdf

Ritzer, G. (2011). Globalization: The essentials. Wiley-Blackwell.

Simpson, K. (2004). 'Doing development': The gap year, volunteer-tourists and a popular practice of development. Journal of International Development, 16(5), 681-692.

Sin, H. L. (2009). Volunteer Tourism: “Involve Me and i Will Learn?” Annals of Tourism Research, 36, 480-501.

Söderman, N., \& Snead, S. L. (2008). Opening the Gap: The Motivation of Gap Year Travellers to Volunteer in Latin America. In Journeys of discovery in volunteer tourism [electronic resource]: International case study perspectives (pp. 118-129). CABI Publishing.

Taylor, J. (2001). Authenticity and Sincerity in Tourism. Annals of Tourism Research, 28(1), 726.

The Gringo Trail. (2020). Fodor's Travel. https://www.fodors.com/world/mexico-and-centralamerica/guatemala/experiences/the-gringo-trail-255996180

Ulmer, T. (2015). A Black helping hand: Collecting the narratives of Black American voluntourists in Trou Baguette, Haiti [PhD Thesis]. Spelman College. 
Urry, J. (1990). The tourist gaze: Leisure and travel in contemporary societies. SAGE Publications, Inc.

Vidon, E. S. (2018). Authenticating the Wilderness: Power, Politics, Performance. In J. M. Rickly \& E. S. Vidon (Eds.), Authenticity \& Tourism: Materialities, Perceptions, Experiences: Vol. First edition (Issue volume 24, pp. 217-235). Emerald Publishing Limited.

Volunteer in Guatemala: Everything you Need to Know \& More! (2020). Go Overseas. https://www.gooverseas.com/volunteer-abroad/guatemala

Vrasti, W. (2013). Volunteer Tourism in the Global South: Giving Back in Neoliberal Times. Routledge.

Wang, N. (1999). Rethinking Authenticity in Tourism Experience. Annals of Tourism Research, 26(2), 349-370.

Wearing, S. (2001). Volunteer tourism: Experiences that make a difference. CABI Publishing. Wearing, S., Deville, A., \& Lyons, K. (2008). The Volunteer's Journey Through Leisure into the Self (K. Lyons \& S. Wearing, Eds.; pp. 63-71). CABI International.

Wearing, S., \& McDonald, M. (2002). The Development of Community-based Tourism: Rethinking the Relationship Between Tour Operators and Development Agents as Intermediaries in Rural and Isolated Area Communities. Journal of Sustainable Tourism, 10(3), 191-206.

Wearing, S., McDonald, M., \& Ponting, J. (2005). Building a Decommodified Research Paradigm in Tourism: The Contribution of NGOs. Journal of Sustainable Tourism, 13(5), $424-439$. 
Wearing, S., \& McGehee, N. G. (2013). Volunteer tourism: A review. Tourism Management, 38, $120-130$.

Wearing, S., Mostafanezhad, M., Nguyen, N., Nguyen, T. H. T., \& McDonald, M. (2018). 'Poor children on Tinder' and their Barbie Saviours: Towards a feminist political economy of volunteer tourism. Leisure Studies, 37(5), 500-514.

Wearing, S., \& Wearing, M. (2006). "Rereading the Subjugating Tourist" in Neoliberalism: Postcolonial Otherness and the Tourist Experience. Tourism Analysis, 11(2), 145-163.

Weiss, R. S. (1994). Learning from strangers: The art and method of qualitative interview studies. The Free Press.

Why Guatemala? (2018). Visit Guatemala. https://visitguatemala.com/por-queguatemala/?lang=en

Woke, adj.2. (2017). In Oxford English Dictionary (Third Edition).

Zahra, A., \& McGehee, N. G. (2013). Volunteer Tourism: A Host Community Capital Perspective. Annals of Tourism Research, 42, 22-45.

Zavitz, K. J., \& Butz, D. (2011). Not That Alternative: Short-term Volunteer Tourism at an Organic Farming Project in Costa Rica. ACME: An International E-Journal for Critical Geographies, 10(3), 412-441. 


\section{APPENDIX A: INFORMED CONSENT FOR VOLUNTEERS}

You are being asked to participate in a research study conducted by Dr. Marion Willetts, Associate Professor of Sociology at Illinois State University and by Hannah Gdalman, a Master's candidate in Sociology and Applied Community and Economic Development Fellow at Illinois State University. The purpose of this study is to explore the range of motivations, perceptions, and experiences of volunteer tourists and host community beneficiaries.

\section{Why are you being asked?}

You have been asked to participate because of your involvement in volunteer tourism in Guatemala. You must be over the age of 18 to participate in this study. Your participation in this study is voluntary. You will not be penalized if you choose to skip parts of the study, not participate, or withdraw from the study at any time.

\section{What would you do?}

If you choose to participate in this study, you will be asked to participate in a semi-structured interview with approximately 15 questions. This interview will last between 45 and 90 minutes and will be audio recorded. The location and time of the interview will be at your convenience. If willing, you will also be asked to participate in a follow-up semi-structured video-chat interview of approximately the same length, which will also be audio recorded. In total, your involvement in this study will last between 1-3 hours.

\section{Are any risks expected?}

The risks associated with this research are no greater than those encountered in your daily conversations discussing your volunteer activities and interactions. Additionally, while all participants will be given pseudonyms, characteristics such as age, gender, and nationality will be described, so there is a risk that participants would be identified.

The researchers are taking steps to safeguard you against these risks by giving you a pseudonym in any research publications. Any notes and transcriptions will also be stored on a password protected and encrypted file on the researcher's personal computer to reduce risks. The names of participants, as well as the name of the volunteer organization and the name of the community in which it is located, will never be identified.

\section{Will your information be protected?}

We will use all reasonable efforts to keep any provided personal information confidential. Participants' names will never be disclosed, however, information regarding gender, age, and nationality of participants may be disclosed in final publications. All information provided will remain confidential. Audio recordings will be deleted by February 2020, and all transcriptions will be password protected on the researcher's computer. Information that may identify you or potentially lead to reidentification will not be released to individuals that are not on the research team. Final publication of this research will be available electronically on the Illinois State University Thesis archives.

However, when required by law or university policy, identifying information (including your signed consent form) may be seen or copied by authorized individuals.

\section{Could your responses be used for other research?}


After your data has been deidentified, your data may be used in other research projects.

\section{Who will benefit from this study?}

There are no direct benefits to participants. However, your participation will help us gain useful knowledge about volunteer tourism in the Guatemalan context. Your responses will be compiled with other responses to determine themes that will serve as a resource for volunteer tourism operations; however, your name will not be disclosed in order to protect your identity.

\section{Whom do you contact if you have any questions?}

If you have any questions about the research or wish to withdraw from the study, contact Hannah Gdalman at 312-607-7992 or hgdalma@ilstu.edu. Dr. Marion Willetts, the ISU faculty advisor for this research, can also be contacted at 309-438-8668 or mcwille@ilstu.edu.

If you have any questions about your rights as a participant, or if you feel you have been placed at risk, contact the Illinois State University Research Ethics \& Compliance Office at (309) 4385527 or (2008).

\section{Documentation of Consent}

Sign below if you are 18 or older and willing to participate in this study.

Signature

Date

You will be given a copy of this form for your records. 


\title{
APPENDIX B: INFORMED CONSENT FOR HOST COMMUNITY MEMBERS
}

\author{
Estimado Sr./Sra.
}

Actualmente me encuentro realizando estudios de postgrado en la Universidad de Illinois State en los Estados Unidos y me gustaría invitarlo a participar nuevamente en mi investigación de tesis. La investigación presente será conducida por Dra. Marion Willetts, Profesora Asociada en Sociología y Licda. Hannah Gdalman, candidata a maestría en Sociología y Desarrollo Comunitario. El propósito de esta investigación consiste en estudiar el turismo sostenible; específicamente las motivaciones, perspectivas y experiencias de los voluntarios y los miembros de la comunidad destina. Mi objetivo es aprender, a través de sus experiencias, los impactos del turismo sostenible en este contexto. Se ha desarrollado una guía de entrevista que podría ser llevada a cabo en forma de conversación.

Este estudio incluye entrevistas con personas, mayores de 18 años, que conozcan sobre o trabajan por este proyecto de turismo sostenible en Guatemala. Su participación es voluntaria. La falta de participar no tendrá ningún efecto en su cargo ni servicios recibidos de la organización. Durante este proceso usted puede: negar su respuesta a cualquier pregunta o declinar su participación en cualquier momento.

La presente entrevista tomaría aproximadamente entre 45 minutos y 2 horas y consiste en aproximadamente 15 preguntas. Esta puede realizarse en un lugar y tiempos adecuados para usted. Yo haría las preguntas y tomaría algunas notas basadas en las respuestas que usted proporcione. La entrevista será grabada.

Los riesgos de la investigación no serán mayores que sus conversaciones cotidianas sobre las actividades del proyecto. La información que usted me proporcione será completamente confidencial y será utilizada solo para fines del estudio. No se usarán nombres y apellidos de los entrevistados, ni de la organización, ni de la comunidad para proteger su identidad. Solo mi Consejera en la Universidad y yo podremos tener acceso a la información para su análisis. Las grabaciones serán destruidas antes de febrero de 2020.

Aunque no existen beneficios directos por su participación en este estudio, los resultados que se generen podrán servir de base para entender más profundamente el turismo sostenible en Guatemala. Cuando se complete el estudio, se publicará un resumen de los resultados a los archivos de la Universidad de Illinois State. Su identidad será protegida. Gracias de antemano por su cooperación. Si usted desea más información en relación con este estudio por favor contacte a la investigadora-estudiante: Hannah Gdalman al correo electrónico: hgdalma@ilstu.edu. También puede comunicarse con mi Asesora Dra. Marion Willetts (correo electrónico: mcwille@ilstu.edu).Si usted tiene cualquier pregunta sobre sus derechos como participante en este estudio por favor contacte Illinois State University Research Ethics \& Compliance Office al teléfono (309) 438-5527 o correo electrónico: IRB@ilstu.edu.

Firma de la investigadora Fecha: 


\section{APPENDIX C: SEMI-STRUCTURED INTERVIEW GUIDE FOR VOLUNTEERS}

1. Ice breaker/warm up -where are you from/general background info

2. Throughout your life, what has been your experience with volunteering? What is the greatest value of volunteering in another country?

3. What is the most important benefit of travel generally?

4. How did you come to volunteer here? Why did you choose Guatemala specifically?

5. What motivated you to come volunteer here?

6. What, if anything, has been surprising or unexpected about your experience so far?

7. How would you characterize your interactions with Guatemalans?

8. What do you hope to contribute during your time volunteering?

9. What do you hope to get out of the volunteering experience?

10. How, if at all, has this experience changed you?

11. What is your impression of your fellow volunteers?

12. How would you define development? Where would you say Guatemala lies in terms of development?

13. What impressions, good or bad, about voluntourism did you have prior to your involvement? On what were those impressions based?

14. What, if anything, would you change about your experience so far?

15. What do you feel that you're contributing to this project? What do you feel you're gaining from it? How do these compare?

16. Is there anything else you'd like to tell me? 


\section{APPENDIX D: SEMI-STRUCTURED INTERVIEW GUIDE FOR HOST COMMUNITY}

\section{MEMBERS}

1. Me gustaría saber un poco más sobre usted. De donde es? Cual es su historia con la organización?

2. Cómo explicará a un extranjero su país? Ciudad? Comunidad?

a. Cuales son los aspectos más y menos favoritos sobre este comunidad?

3. Cual es su experiencia con voluntarios extranjeros? Turistas extranjeras?

4. En qué circunstancias ( si es que interactúan), interactúan con turistas y/o voluntarios extranjeros?

5. Como se describe Ud. sus interacciones con los voluntarios? Con las turistas?

a. La comunicación? Semejanzas culturales? Diferencias culturales?

6. Que tan bien comunica usted con los voluntarios?

7. En cuales maneras (como mucho) son similares o distintas los voluntarios y los turistas?

a. Por que?

8. Por que, según usted, vienen aquí a Guatemala las turistas? Por que no vayan a otro lugar?

a. Por qué es Guatemala un destino especial? Único? Qué significado tiene Guate para usted?

9. Como se define usted el desarrollo? En respeto al desarrollo, dónde se sitúa Guatemala?

10. Por que, según usted, vienen aquí los voluntarios a [nombre de sitio]?

a. Que significado o importancia tiene esta organización a usted?

11. Que, si algo, se han contribuido los voluntarios a usted/la comunidad/la organización?

a. Qué pasaría si no vinieran mas voluntarios aquí?

12. Me contara sobre un tiempo cuando habían pocos voluntarios? Muchos voluntarios?

13. Que, si algo, contribuye usted a los voluntarios? A la organización?

14. Siente usted que gana o recibe mas de, o da mas a, los voluntarios? Por que?

15. Qué le ha sorprendido o qué ha sido inesperado sobre su experiencia con los voluntarios?

16. Me contara su historia favorita sobre un voluntario extranjero?

17. Qué cambiaría sobre la manera en que operan o trabajan los voluntarios aquí?

18. Hay algo mas que le gustaría compartir conmigo? 